\title{
Natural history and conservation of the rediscovered Hula painted frog, Latonia nigriventer
}

\author{
R.G. Bina Perl ${ }^{1,2,8}$, Sarig Gafny ${ }^{2}$, Yoram Malka ${ }^{3}$, Sharon Renan ${ }^{4}$, Douglas C. Woodhams ${ }^{5}$, Louise Rollins-Smith ${ }^{6,7}$,
} James D. Pask ${ }^{6}$, Molly C. Bletz ${ }^{1}$, Eli Geffen ${ }^{4}$, Miguel Vences ${ }^{1}$

${ }^{1}$ Division of Evolutionary Biology, Zoological Institute, Braunschweig University of Technology, Mendelssohnstr.4, 38106 Braunschweig, Germany

${ }^{2}$ School of Marine Sciences, Ruppin Academic Center, Michmoret 40297, Israel

${ }^{3}$ Israel Nature and Parks Authority, 3 Am Ve'Olamo Street, Jerusalem 95463, Israel

${ }^{4}$ Department of Zoology, George S. Wise Faculty of Life Sciences, Tel Aviv University, Tel Aviv 69978, Israel

${ }^{5}$ Department of Biology, University of Massachusetts Boston, 100 Morrissey Blvd., Boston, Massachusetts, 02125 USA

${ }^{6}$ Departments of Pathology, Microbiology and Immunology and of Pediatrics, Vanderbilt University School of Medicine, Nashville, Tennessee, 37232 USA

${ }^{7}$ Department of Biological Sciences, Vanderbilt University, Nashville Tennessee, 37235 USA

${ }^{8}$ E-mail: r.perl@tu-braunschweig.de

Key words: Amphibia, antimicrobial peptides, Anura, Batrachochytrium dendrobatidis, habitat, skin microbiota, tadpole

\begin{abstract}
Dramatic global amphibian declines have recently led to an increased concern for many species of this animal class. The enigmatic Hula painted frog (Latonia nigriventer), the first amphibian to be declared extinct but unexpectedly rediscovered in 2011, has remained one of the rarest and most poorly understood amphibians worldwide. Gathering basic biological information on this species, along with an understanding of its disease-related threats remains fundamental for developing risk assessments and conservation strategies. Our surveys in recent years confirmed that $L$. nigriventer is a localised species with elusive habits. The species appears to follow an opportunistic breeding phenology and has a tadpole morphology similar to its well-studied sister group Discoglossus. However, the adults' extended annual presence in the aquatic habitat is a major difference from species of Discoglossus. We detected the amphibian chytrid fungus, Batrachochytrium dendrobatidis $(B d)$, in northern Israel and on Hula painted frogs but did not observe any signs of chytridiomycosis in this species. Our preliminary data on aspects of the innate immunity of $L$. nigriventer suggest that the skin mucosome of this species contains antimicrobial peptides and a bacterial community differing from other syntopic frogs (Pelophylax bedriagae). The combined knowledge of both natural history and innate immunity of L. nigriventer provides valuable insights to direct future research and conservation management of this critically endangered frog species.
\end{abstract}

\section{Contents}

Introduction 11

Material and methods
Field surveys and sampling ........................................................ 14

Adult and juvenile morphometrics and colour .................. 14

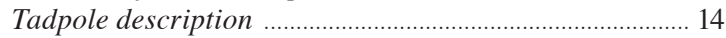

Vocalisations ........................................................................ 15

Bacterial communities and Bd/Bsal screening ................... 15

Skin peptides collection and anti-Bd growth

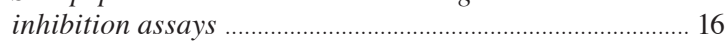

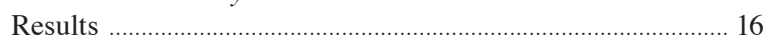

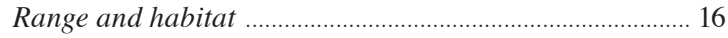

Activity patterns and movement ............................................. 17

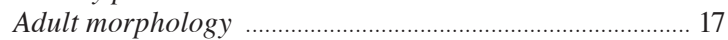

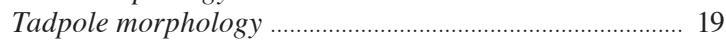

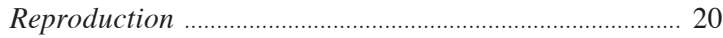

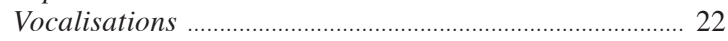

Bd/Bsal screening, skin bacterial community,

and defensive skin peptides ........................................... 23

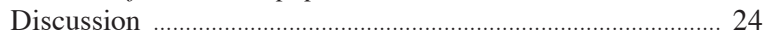

Acknowledgements .................................................................. 29

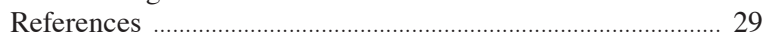

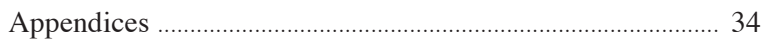

\section{Introduction}

The Hula painted frog (Latonia nigriventer (Mendelssohn and Steinitz, 1943)) was first discovered in the eastern part of the Hula Valley in northern Israel on 22 March 1940 (Mendelssohn and Steinitz, 1943; Fig. 1 A-B) and appears to be strictly endemic to this area. When the draining of the Lake Hula marshes in the 1950 s caused the extinction or local disappearance of several species of this area (Dimentman et al., 1992; 

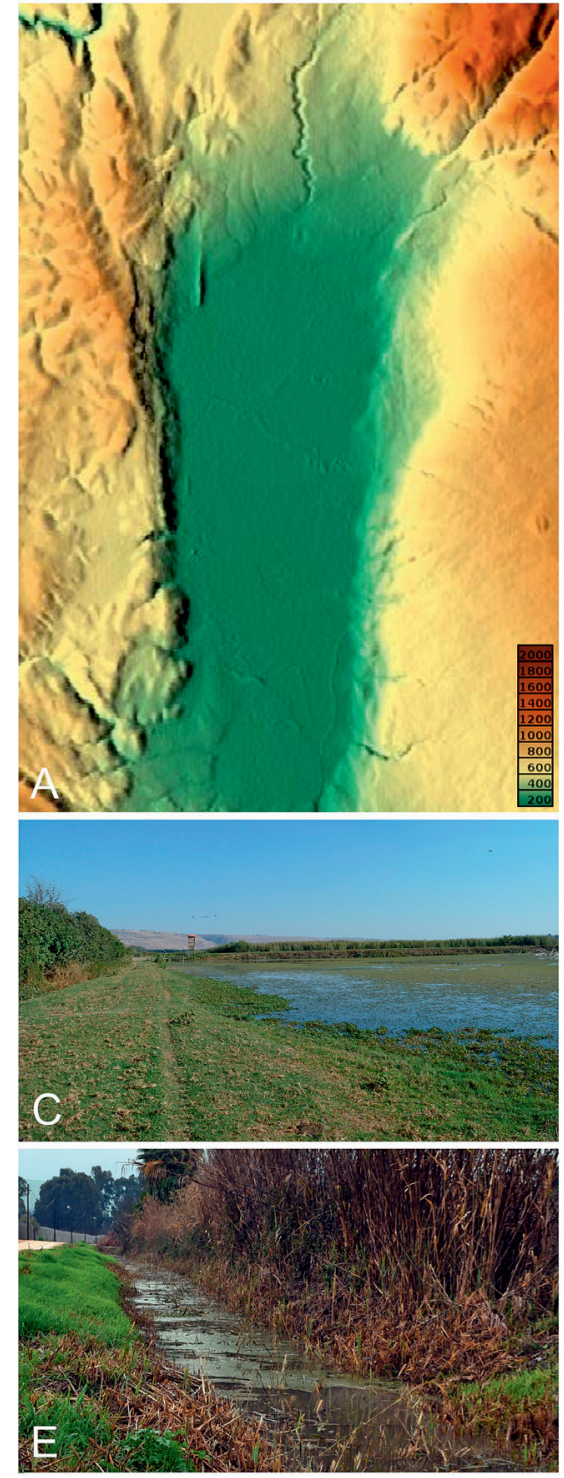
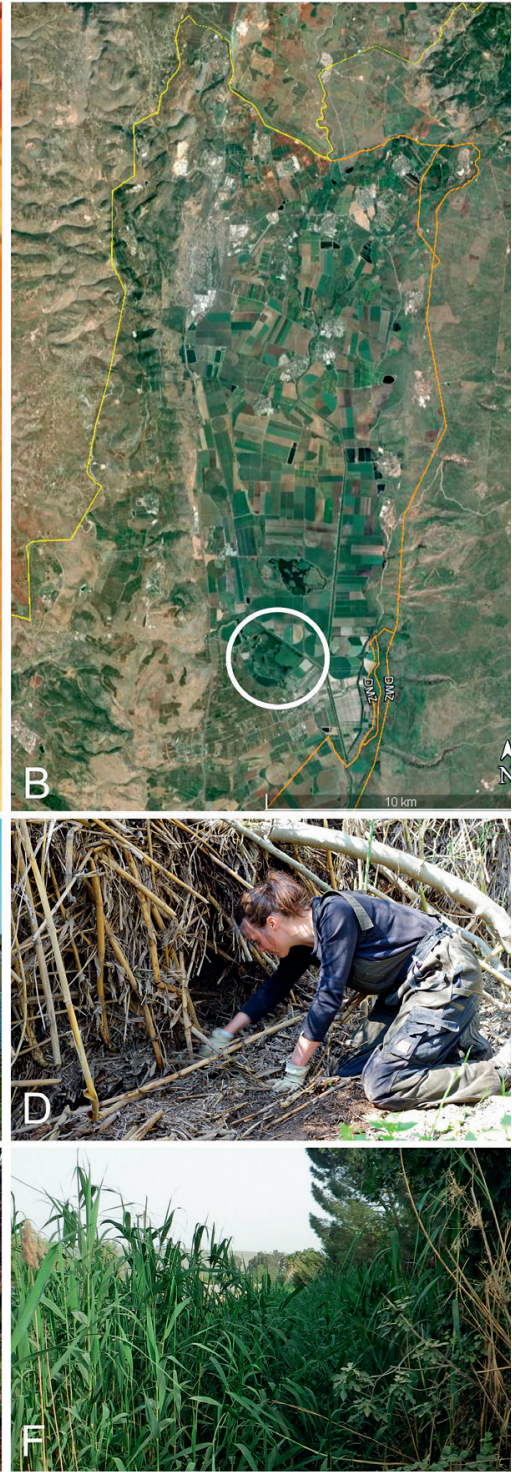

Fig. 1. Habitat of Latonia nigriventer. A) Relief map of the Hula Valley (legend shows surface elevation in meters); B) satellite image of the Hula Valley showing the location of the Hula Nature Reserve (indicated by the white circle); C) water body close to the finding sites within the Hula Nature Reserve; D) typical finding site within the Hula Nature Reserve; ditch in Yesod HaMa'ala after (E) and before $(\mathrm{F})$ the vegetation was trimmed by local authorities.
Goren and Ortal, 1999; Payne, 2012), the dramatic ecosystem change most likely also caused the decline of L. nigriventer. After the then last known individual was collected in 1955 (Steinitz, 1955), the species was the first of 37 anuran species to be officially declared extinct by the IUCN in 1996 (Baillie et al., 2010).

Almost 40 years after the drainage, the Hula Valley was partly re-flooded and signs of ecological restoration were observed (Kaplan et al., 1998; Cohen-Shacham et al., 2011; Kaplan, 2012). Subsequently, in November 2011, a single postmetamorphic individual of L. nigriventer was discovered in the Hula Nature Reserve that protects the last remnant of the former
Lake Hula marshes. In the following two years, thirteen more postmetamorphic individuals were captured. All those recently discovered individuals were observed within this same tiny patch of habitat (Biton et al., 2013; SG, YM, EG personal observations).

Painted frogs (Discoglossus) belong to one of the oldest anuran clades (Alytidae) which dates back to the Jurassic. The Hula painted frog was originally described in this genus and had been classified as such until 2013. However, based on recent genetic and osteological analyses the species was found to be a sister to a clade of all remaining Discoglossus and was assigned to Latonia, a genus of fossil giant frogs known from the Miocene 


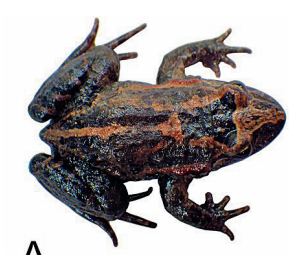

A
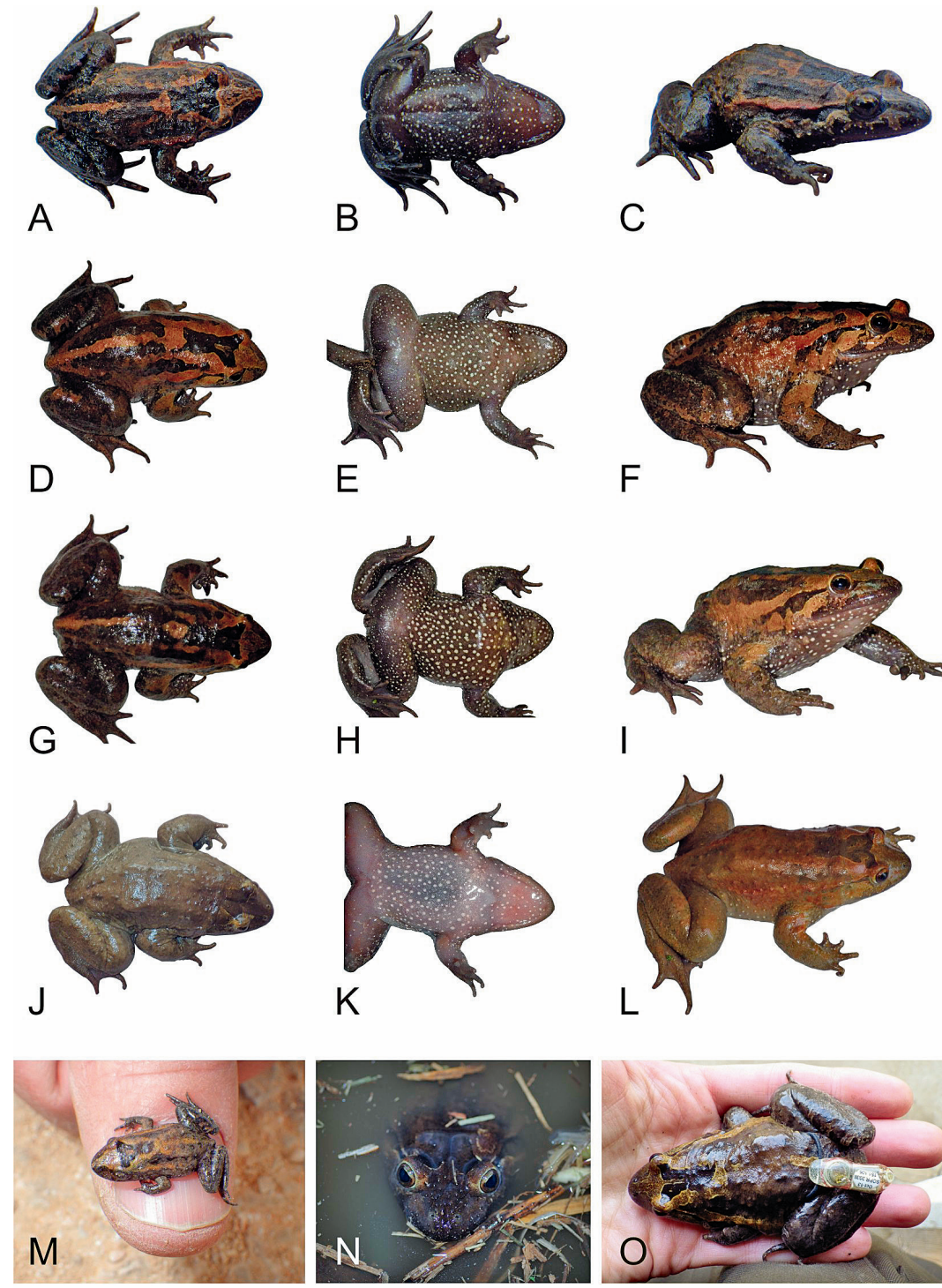
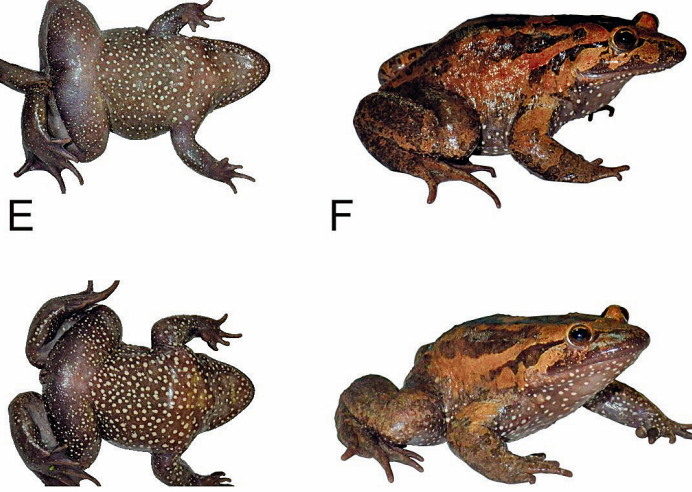

$\mathrm{H}$
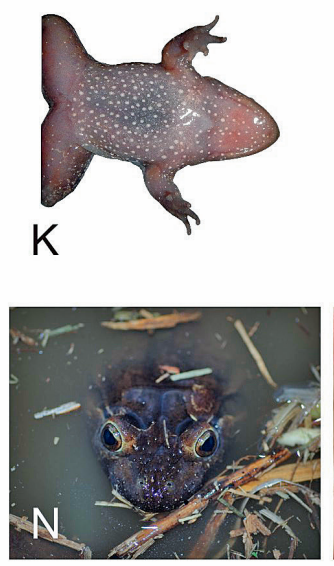
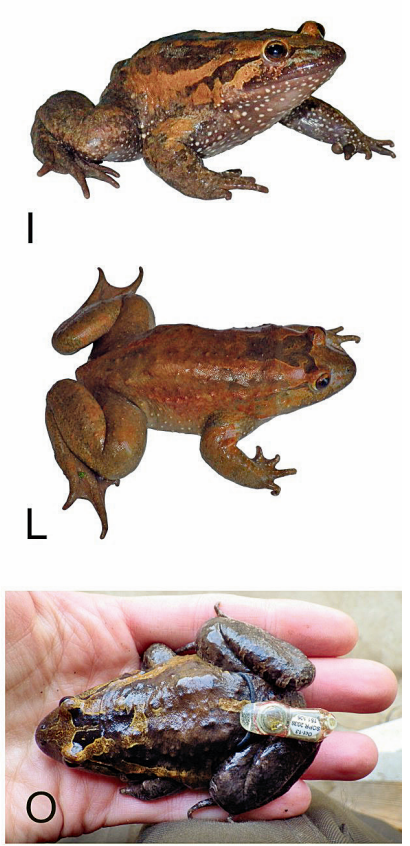

Fig. 2. General appearance and colour variants of Latonia nigriventer. Juvenile individual (SVL $30.4 \mathrm{~mm}$ ) in dorsal (A), ventral (B) and lateral (C) view; adult female (SVL $100.5 \mathrm{~mm}$ ) in dorsal (D), ventral (E) and lateral (F) view; adult male (SVL $98.2 \mathrm{~mm}$ ) in dorsal $(\mathrm{G})$, ventral $(\mathrm{H})$ and lateral (I) view; J) dark adult male (SVL $114.0 \mathrm{~mm}$ ) displaying almost no characteristic pattern on dorsum; K) medium-sized juvenile (SVL $43.0 \mathrm{~mm}$ ) displaying a pale translucent venter; L) adult female (SVL $102.3 \mathrm{~mm}$ ); M) smallest wild caught $L$. nigriventer individual (SVL $16.2 \mathrm{~mm}$ ); $\mathrm{N})$ housed $L$. nigriventer individual (SVL $103 \mathrm{~mm}$, female) only displaying the rostral portion of the head while the rest of the body is submerged; O) adult female (SVL $81 \mathrm{~mm}$ ) carrying a transmitter. through Pleistocene but considered to be extinct since (Biton et al., 2013). The fact that L. nigriventer is the sole surviving species of an ancient clade, and thus alone represents a high proportion of alytid phylogenetic diversity, calls for special attention to ensure its survival. To date, almost nothing is known about the natural history of this ancient, only recently rediscovered frog that still ranges among the rarest amphibians in the world. Apart from the brief tadpole and adult descriptions published by Mendelssohn and Steinitz (1943), the available information on its sister group Discoglossus has remained the only reference to speculate about the natural history of L. nigriventer.
Effective conservation of this unique species requires precise knowledge on its distribution range, basic ecology, and reproductive biology to (i) allow for a definition of adequate conservation priorities targeting aquatic and terrestrial landscape structures in the highly transformed Hula Valley, and (ii) enable future in-situ or ex-situ breeding initiatives. In addition, knowledge about the presence of the chytridiomycete fungus, $B a$ trachochytrium dendrobatidis Longcore, Pessier and Nichols, $1999(B d)$, in the Hula Valley as well as on innate skin defensive mechanisms of $L$. nigriventer against this pathogen, e.g. mediated through beneficial skin bacteria or antimicrobial peptides (Colombo et al., 
2015), are a valuable piece of information for an integrated risk assessment of this species.

Here we have compiled observations and data on multiple aspects of the natural history of L. nigriventer. We also provide the first evidence for the presence of $B d$ in northern Israel as well as preliminary information regarding the innate immune defences and skin microbial community of L. nigriventer, to aid future conservation management of this critically endangered species.

\section{Material and methods}

\section{Field surveys and sampling}

We carried out eight field surveys between November 2013 and September 2015 at numerous amphibian habitats over ca. $177 \mathrm{~km}^{2}$ in the Hula Valley. Daytime surveys for $L$. nigriventer involved searching terrestrial habitats as well as various water bodies where we used dip nets to search for adults, tadpoles and egg clutches. Night surveys only involved visual inspection of water bodies and their banks. To minimise disturbance, sites were usually not inspected more than twice a week. Equipment and shoes were either completely dried or disinfected with Virkon S or 10\% bleach solution between locations (i.e. those not connected by waterways) following Johnson et al. (2003). Detailed coordinates of confirmed locations are not published to avoid disturbance and collecting, but have been communicated to the Israel Nature and Parks Authority.

Metamorphosed individuals were captured with gloved hands, photographed in dorsal and ventral views and morphometric measurements were taken. We collected tissue and buccal swabs for assessing genetic variation, and took skin and cloacal swabs for exploring the microbial communities of L. nigriventer and other local amphibians. Skin swabs were also used for $B d$ screening (Hyatt et al., 2007). Before swabbing, frogs were rinsed with sterilised distilled water to remove transient bacteria (Culp et al., 2007; Lauer et al., 2007; Rebollar et al., 2014). Water volume was adjusted based on SVL (50-150 ml). The skin of each individual was swabbed dorsally and ventrally using two separate swabs with each side receiving 10 strokes.

Tissue samples and buccal swabs were directly stored in 95-99\% ethanol, while skin swabs were immediately placed on ice and transferred to freezer storage $\left(-20^{\circ} \mathrm{C}\right)$ within 8 hours. All metamorphosed individuals were released back to their collection site after examination. None were sacrificed but dead individuals (e.g. due to predation, road kills) were preserved in ethanol. Several tadpoles died shortly after capture and were fixed in $70 \%$ ethanol and later preserved in $70 \%$ ethanol or $5 \%$ formalin.

External transmitters (SOPR-2038; Wildlife Materials International, Inc.) were fitted to seven large (> 70 $\mathrm{mm}$ ) individuals with an elastic waistband. Specimens were kept in a terrarium for up to three days to ensure that the waistband was not causing undue harm. Released individuals were tracked with a TRX-16 receiver and 3-element folding antenna (Wildlife Materials International, Inc.). Tracking was completed twice a day for up to 18 days, but individuals were only visually inspected every second or third day in order to minimise disturbance (Fig. 2 O).

\section{Adult and juvenile morphometrics and colour}

In adult and juvenile frogs the following measurements were taken with a calliper to the nearest $0.1 \mathrm{~mm}$, and weight was taken with a digital scale or Pesola spring scale (precision: $0.1 \mathrm{~g}$ ): horizontal eye diameter (ED), horizontal eye neck fold to snout (FS), hand length (HAL), head width at eyes (HW), interorbital distance (IOD), length of elbow to finger tip (LE), tip of characteristic colour patch on forehead to snout (PS), snout-vent length (SVL), tarsal length (TSL), weight (W), webbing formula is given following Blommers-Schlösser (1979).

We calculated the body condition of each adult individual with the relative mass $\left(W_{\mathrm{r}}\right)$ condition index as described in Sztatecsny and Schabetsberger (2005). The obtained ratios were statistically analysed by Mann-Whitney-U test implemented in R (v 3.2.4).

The distinctive ventral and dorsal natural markings displayed by each metamorphosed frog were used for identifying recaptured individuals.

\section{Tadpole description}

Morphological description and measurements of tadpoles (to the nearest $0.1 \mathrm{~mm}$ ) were obtained using a stereomicroscope (Zeiss Discovery V12) following landmarks, terminology and definitions of Altig and McDiarmid (1999). Developmental stages were identified following Gosner (1960). Labial tooth row formula (LTRF) follows Altig and McDiarmid (1999) but labial teeth are named 'keratodonts'. For a list of morphological characters measured and abbreviations used, see tadpole description in Appendix 3. 


\section{Vocalisations}

Calls probably representing advertisement calls were recorded in February 2015 from two adult males (SVL 114 and $121 \mathrm{~mm})$ kept in a terrarium $(\mathrm{L} \times \mathrm{W} \times \mathrm{H}=71$ $\times 50.5 \times 40 \mathrm{~cm}$; filled with water $(7 \mathrm{~cm}$ depth), with some reed and grass material) overnight together with two females (SVL 103 and $128 \mathrm{~mm}$ ). Calls were recorded above water with the built-in microphone of a waterproof camera (Pentax; WG-II) and an acoustic recorder (SM2+; Wildlife Acoustics Inc.) that also recorded air temperature. Water temperature was measured by a Thermochron iButton datalogger. Recordings were analysed at a sampling rate of $44.1 \mathrm{kHz}$ and 16-bit resolution with Cool Edit Pro 2.0. We measured interval length between calls and six acoustic features for each call, including call duration, expiratory note duration, inspiratory note duration, dominant frequency of the total call, and of presumed expiratory and inspiratory notes (Glaw and Vences, 1991). Vocalisations were illustrated using the R package 'seewave' (Sueur et al., 2008). Call recordings were submitted to the FonoZoo sound archive (www.fonozoo.org); accession numbers 9850-9854.

\section{Bacterial communities and Bd/Bsal screening}

A screening for the two chytridiomycete pathogens, $B d$ and B. salamandrivorans Martel, Blooi, Bossut and Pasmans, 2013 (Bsal), was conducted in L. nigriventer, Pelophylax bedriagae (Camerano, 1882), Hyla savignyi Audouin, 1827 and Salamandra infraimmaculata Martens, 1885 from seven localities in and around the Hula Valley, to identify the possible presence or absence of these two amphibian pathogens from this region in Israel. Skin microbial communities were analysed for L. nigriventer and the syntopic Levant water frogs ( $P$. bedriagae).

DNA was extracted from swabs with the PowerSoil ${ }^{\circledR}$ DNA Isolation Kit (Mo Bio Laboratories, Carlsbad, Ca, USA), following the Earth Microbiome project protocol (http://www.earthmicrobiome.org) except that centrifuge conditions were adjusted to accommodate reduced rotor speed.

$B d / B s a l$ screening was performed by duplex quantitative PCR (in duplicate) according to the protocol of Blooi et al. (2013).

To characterise skin bacterial communities, we PCR-amplified the V4 region of the bacterial $16 \mathrm{~S}$ rRNA gene with dual-indexed primers (Kozich et al., 2013). PCRs were completed in duplicate following
Sabino-Pinto et al. (2016). Negative controls were included to check for contamination. PCR products were combined for each sample and roughly quantified on $1 \%$ agarose gels. Approximately equal concentrations of PCR amplicons from each sample were pooled, gel purified using the MinElute gel extraction kit (Qiagen). DNA concentration was determined using a Qubit 2.0 and equimolar amounts were sequenced on an Illumina MiSeq platform at the Helmholtz Center for Infection Research in Braunschweig, Germany, using pairedend $2 \times 250$ v2 chemistry. Sequences were deposited in the NCBI Short Read Database (SRA BioProject PRJNA326938).

Sequences were processed with the Quantitative Insights Into Microbial Ecology (QIIME; v 1.9.1.) pipeline for Linux (Caporaso et al., 2010). Raw forward and reverse reads of each sample were joined using Fastq-join under default settings (Aronesty, 2011, 2013). After quality filtering with default settings to remove low-quality sequences, we further filtered the reads by length (250-253 bp; usegalaxy.org) and removed chimeric sequences on a per sample basis using de novo usearch61 chimera detection within QIIME (http://drive5.com/usearch/usearch_docs.html; Edgar et al., 2011). Sequences were clustered into bacterial operational taxonomic units (OTUs) with a sequence similarity threshold of $97 \%$ using an open reference OTU-picking strategy (Rideout et al., 2014, http://qiime. org/tutorials/open_reference_illumina_processing. html). SILVA 119 (24 July 2014 release; https://www. arb-silva.de) served as reference database and UCLUST (Edgar, 2010) was used in the de novo clustering steps. The most abundant sequences of each OTU were selected as representative sequences and aligned using PyNAST (Caporaso et al., 2010). OTUs with less than $0.005 \%$ of total reads were removed from the data set following Bokulich et al. (2013). Taxonomy was assigned using the RDP classifier (Wang et al., 2007) with the SILVA 119 taxonomy and representative sequences as reference, and a phylogenetic tree built using FastTree (Price et al., 2010) adhering to QIIME's standard procedures. We also used QIIME to generate a rarefaction curve to confirm that an asymptote was reached for all samples (see S1 in the Supplement). Lastly, we rarefied the data to 1000 sequences to correct for sample depth heterogeneity and calculated beta diversity using the weighted UniFrac distance metric in QIIME.

We tested for (i) differences in dorsal and ventral skin bacterial communities of L. nigriventer, (ii) seasonal variation of the skin microbial community, and 
(iii) species-specific differences between L. nigriventer and $P$. bedriagae. Statistical analyses were done with PRIMER v7 software (Plymouth Routines In Multivariate Ecological Research; Clarke and Gorley, 2015). PERMANOVA analyses were performed using 999 permutations and associated plots were generated by principal coordinates analysis (PCoA). Core bacterial communities, defined as OTUs present in at least $75 \%$ of the samples and overlap among core communities was visualised with Venn diagrams drawn with VENNY 2.0 (http://bioinfogp.cnb.csic.es/tools/venny/).

Skin peptides collection and anti-Bd growth inhibition assays

Skin secretions of two L. nigriventer individuals were collected from two sterile polyethylene bags (WhirlPak, Nasco) in which they were kept prior to measurement, by washing the bags with $\sim 50 \mathrm{ml}$ of sterile water. Samples were then frozen until further processing. After defrosting, $2 \mathrm{ml}$ of the skin secretion wash was removed for direct testing against $B d$. The remaining volume from each sample was acidified to a final volume of $1 \% \mathrm{HCL}$ to inactivate potential endogenous peptidases (Resnick et al., 1991; Steinborner et al., 1997) and immediately loaded onto C-18 Sep-Pak cartridges (Waters Corporation, Milford, Massachusetts, USA) which were then stored in vials with $2-5 \mathrm{ml}$ of $0.1 \% \mathrm{HCL}$ until further processing.

We eluted the peptides bound to the Sep-Paks with $70 \%$ acetonitrile, $29.9 \%$ water, and $0.1 \%$ trifluoracetic acid $(\mathrm{v} / \mathrm{v} / \mathrm{v})$ and centrifuged them under vacuum to concentrate them to dryness. After Sep-Pak purification, we determined the total concentration of the recovered skin peptides by Micro BCA Assay (Pierce, Rockford, Illinois, USA) following manufacturer's instructions, except that we used bradykinin (RPPGFSPFR; Sigma) to establish a standard curve (Rollins-Smith et al., 2002). Skin peptides were analysed by matrix-assisted laser desorption/ionisation mass spectrometry (MALDI MS) as described in Pask et al. (2012). We analysed each sample by averaging signals from 250 consecutive laser shots. Mass spectrometry data was acquired in the mass/ charge $(\mathrm{m} / \mathrm{z})$ range 500 to 7,000 , truncated at $\mathrm{m} / \mathrm{z} 4,000$ and baseline-corrected with Data Explorer v4.4 (Applied Biosystems). The peak values shown represent the monoisotopic mass, $[\mathrm{M}+\mathrm{H}]^{+}$. A few signals may show secondary peaks 22 mass units greater than the primary peak and probably represent a peptide plus sodium adduct $[\mathrm{M}+\mathrm{Na}]^{+}$. Spectra may also show peaks at $\mathrm{m} / \mathrm{z} 568.1$ and 650.0 because of matrix or background signal.
We conducted in vitro growth inhibition assays of the enriched skin peptide mixtures against two $B d$ isolates (JEL 197 and 'Section Line') (Longcore et al., 1999; Piovia-Scott et al., 2015) as described previously (Rollins-Smith et al., 2006; Ramsey et al., 2010; Holden et al., 2015). Briefly, B. dendrobatidis zoospores were grown on $1 \%$ tryptone agar for one week at $23^{\circ} \mathrm{C}$. Freshly isolated zoospores were added $\left(5 \times 10^{4} / 50 \mu 1,5\right.$ replicates $)$ in tryptone broth to a $96-$ well flat-bottom microtiter plates with $50 \mu 1$ of a serially diluted mixture of skin peptides dissolved in HPLC-grade water. Positive control wells contained zoospores and $50 \mu \mathrm{l}$ HPLC water. Negative control wells contained heat-killed zoospores $\left(60^{\circ} \mathrm{C}\right.$ for 10 minutes) and $50 \mu \mathrm{l}$ of HPLC water. Plates were incubated at $23^{\circ} \mathrm{C}$ for one week, and growth was measured as an increased optical density at $490 \mathrm{~nm}\left(\mathrm{OD}_{490}\right)$ using an MRX Microplate Reader (Dynex Technologies, Inc., Chantilly, VA, USA). Percent growth was calculated as follows: OD at Day $7-$ OD at Day 0 for test sample / OD at Day 7 - OD at Day 0 for positive control.

We performed $B d$ growth inhibition assays with the direct skin secretion solution following the methods explained above, with $50 \mu 1$ of the direct skin secretion solution being added to the microtiter plate instead of the peptide dilutions. The assays were completed with the isolate $B d$ VMV 813.

\section{Results}

\section{Range and habitat}

We detected $L$. nigriventer at the known and newly identified sites within the Hula Nature Reserve, and at another location, about $1 \mathrm{~km}$ southeast of the reserve borders near the small village Yesod HaMa'ala (Fig. 1 C-F). In total, we observed 64 adult females, 42 adult males, 29 juveniles (Fig. 2) and 40 tadpoles. Of these, six middle-sized to large individuals (SVL 33.8-76.8 $\mathrm{mm}$ ) were discovered within the reserve, while 112 medium to large-sized individuals (SVL 43.0-128.4 $\mathrm{mm}$ ), 19 small individuals (SVL 16.2-30.1 mm; Fig. 2 M) as well as tadpoles at Gosner stages 25-34 were recorded at Yesod HaMa'ala. Based on our specimen records we estimate L. nigriventer to occupy an area of at least $6.5 \mathrm{~km}^{2}$, but the number of active reproductive sites is uncertain.

The species was found to exploit different kinds of terrestrial and aquatic habitats: 
(1) In the Hula Nature Reserve all individuals were discovered in terrestrial habitats. As a former part of the Hula marshes and lake, the organic soil at this site is peaty, damp and loose, and covered by a ca. $20-30 \mathrm{~cm}$ layer of humid decomposed leaf litter. Most individuals (including 9 of the 14 individuals found prior to our surveys) were found beneath this layer within a dense thicket of blackberry (Rubus sanguineus Frivaldszky, 1835), reeds (Phragmites australis (Cavanilles) Trinius Ex Steudel, 1840) and occasionally fig trees (Ficus carica Linnaeus, 1753). The majority of the reserve's water bodies are lentic and about $20-30 \%$ of the permanently flooded area is covered by dense stands of reeds and Papyrus sedge (Cyperus papyrus Linnaeus, 1753). It is, however, uncertain which of the water bodies of the Hula Nature Reserve are used by L. nigriventer as no individuals were found here in their aquatic habitat, and no eggs or larvae were detected.

(2) At the site near Yesod HaMa'ala, all individuals were found in the water or at the slopes of a $\sim 600 \mathrm{~m}$ long ditch. This ditch has a permanent source of water from a small spring and dense vegetation both in and next to the water. The water is very slowly flowing and depth is substantial (up to ca. $150 \mathrm{~cm}$ ) but starting at depths of ca. 10-100 cm. A deep layer of mud covers the bottom of the ditch and aquatic vegetation covers much of the water's surface (comprising dense P. australis growths, water lettuce (Pistia stratiotes Linnaeus, 1753), and duckweed, Lemna minor Linnaeus, 1753). At the edges of the ditch, the mineral soil is compressed, sandy and in the dry season less damp than in the reserve. Individuals in terrestrial habitat were detected either beneath dried or half-dried grass tufts, or in natural cavities or small burrows at the water edge dug by semi-terrestrial freshwater crabs (Potamon potamios (Olivier, 1804)) or small mammals. The Latonia individuals encountered at this site displayed a strikingly high percentage of injury. Of the 112 medium to large-sized frogs (> $42 \mathrm{~mm}$ ), $28 \%$ had old or recent minor injuries mainly on the hind limbs (Fig. 3), while such injuries were not detected in juvenile frogs or in individuals found in the Hula Nature Reserve. However, the ditch is less frequently visited by migrating birds or larger mammals and has fewer fish species than other, major water bodies in the Hula Nature Reserve (see S2 in the Supplement).

\section{Activity patterns and movement}

All tadpoles were caught in shallow parts of the Yesod HaMa'ala ditch. Metamorphosed individuals were ob- served either within humid leaf litter in the close vicinity to a perennial water body, directly at the water's edge or in the water. The majority of the individuals discovered during winter months - especially during the first longterm field trip from November 2013 through March 2014 - were land-dwelling juveniles of snout-vent lengths of 20-30 mm. Adults were mostly detected in the water from February through September, which may correspond to the breeding period (Fig. 4).

In general, the frogs appeared to be mainly nocturnal and could frequently be observed in the water after nightfall. Individuals were found solitarily and were not observed in aggregations.

Upon capture, terrestrial individuals first froze in their movement and then tried to escape forward by either slowly jumping or walking. Walking individuals retracted their eyes. Whenever the density of the soil allowed, they forced their way underground head first with retracted eyes by strongly pushing back all limbs in a walking manner. The increased secretion of viscous skin mucus further facilitated the movement through soil or vegetation. Individuals observed at night in the water were usually submerged with exception of the rostral portion of the head (Fig. $2 \mathrm{~N}$ ). Upon disturbance, they immediately tried to retreat into the water and escape head first into dense thickets of aquatic plants and roots. They were more easily scared (e.g. by our electric torches) than P. bedriagae or $H$. savignyi. While being handled, adults of both sexes uttered release calls that were similar to the presumed advertisement calls described below but less regular and less intense.

For the frogs for which displacement was recorded by capture-recapture, the distances moved were $<20 \mathrm{~m}$ $(\mathrm{N}=10),>20 \mathrm{~m}<100 \mathrm{~m}(\mathrm{~N}=4)$ and $\leqq 100 \mathrm{~m}(\mathrm{~N}=5)$ (Table 1). Three radio-tracked frogs moved no more than $2 \mathrm{~m}$ over periods of 5,5 and 18 days, respectively.

\section{Adult morphology}

Latonia nigriventer is a rather inconspicuously coloured, robust frog reaching large sizes of 69.0-128.4 $\mathrm{mm}$ in females and 66.6-121.4 $\mathrm{mm}$ in males. In the observed individuals, webbing was strongly developed suggesting a substantial aquatic adaptation, and hind limbs were comparatively short. The head was rather flat and the iris heart-shaped. A distinct transversal dermal fold was present in the neck. The colour pattern was similar in all individuals despite differences in distinctness and contrast (Fig. 2). An incomplete mid-dorsal band of the lighter colour was almost always visible 

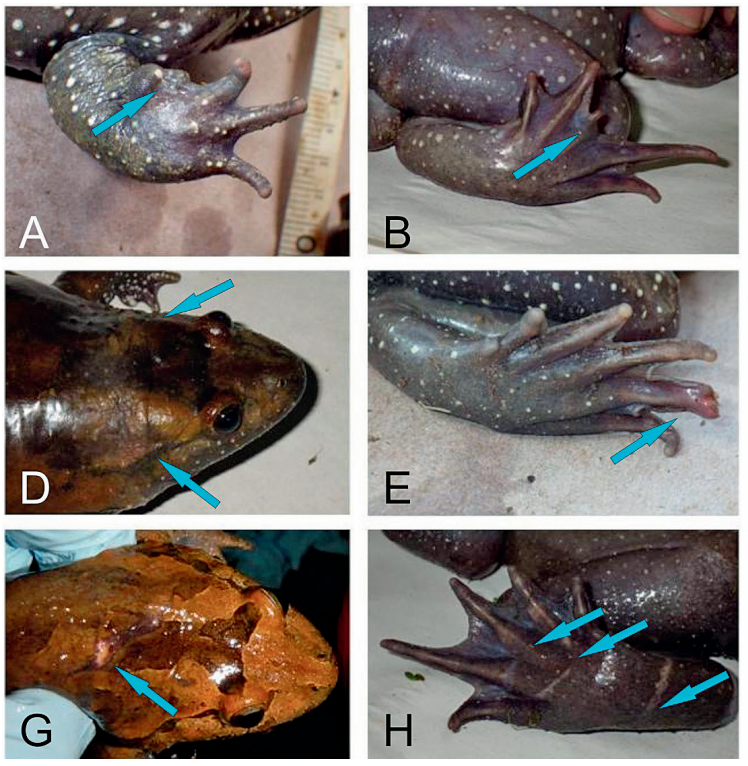
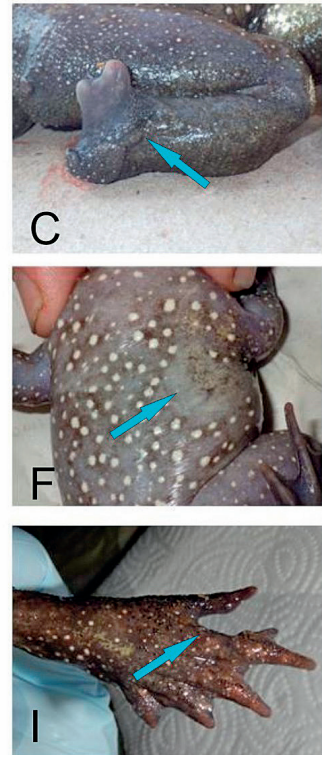

Fig. 3. Types of injuries observed in medium-sized and large individuals of Latonia nigriventer captured in Yesod HaMa'ala. Blue arrows indicate the respective injuries: A) male individual (SVL $121.4 \mathrm{~mm}$ ) lacking index finger; B) individual of unknown sex (SVL 65.8 $\mathrm{mm}$ ) lacking third toe; C) male individual (SVL $101.3 \mathrm{~mm}$ ) lacking left foot; D) female individual (SVL $110.9 \mathrm{~mm}$ ) with old scarring stretching all over neck; E) female individual (SVL 88.1 $\mathrm{mm}$ ) with fresh injury on left fourth toe; F) female individual (SVL $95.0 \mathrm{~mm}$ ) with old scarring on left lateral side; G) male individual (SVL $105.0 \mathrm{~mm}$ ) with fresh puncture wound on neck; H) male individual (SVL $106.2 \mathrm{~mm}$ ) with old scarring on right foot; I) male individual (SVL $98.0 \mathrm{~mm}$ ) with injured webbing. Images not to scale. in the posterior part of the dorsum. The venter was black to grey with a distinct pattern of white spots which corresponded to raised tubercles in adults. For a detailed morphological description of adults, see Appendix 1; for data and measurements of the holotype, see Appendix 2.

From mid-February until mid-September, i.e. during the presumed breeding season, we observed distinct dark nuptial pads and more or less distinct black, keratinised excrescences on the thorax, ventral part of arms and thighs, plantar surfaces as well as on the outer edge of the webbing in males. In single cases, excrescences were also present on dorsal surface of feet. In females, such structures were distinct only on plantar surfaces and to some degree on the webbing edge, and in very rare cases, single excrescences were seen on the thoracic region (Fig. 5). The excrescences on the body skin had the form of isolated spicules whereas at the webbing edges they formed dense aggregations. The smallest male with clearly developed nuptial pads had a snout-vent length of $66.6 \mathrm{~mm}$, and

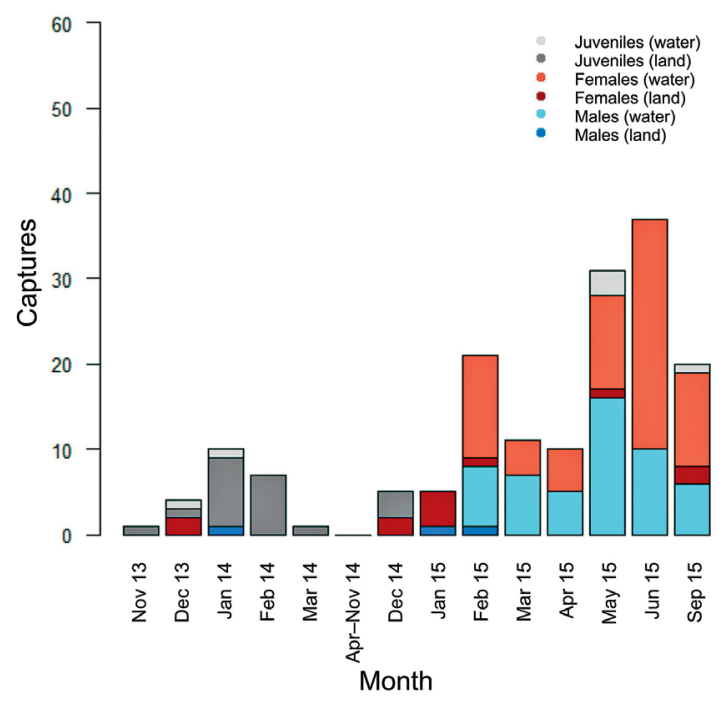

Fig. 4. Number of individuals of Latonia nigriventer captured across months. All individuals below $66 \mathrm{~mm}$ were considered juveniles, males and females were distinguished on the basis of their foot webbing and the presence of nuptial pads in males.

Table 1. Details on recaptured Latonia nigriventer individuals. Averages (min-max) are given for number of days after previous capture and covered distances. $\mathrm{F}=$ female; $\mathrm{J}=$ juvenile; $\mathrm{M}=$ male; $\mathrm{na}=$ GPS data partly missing, no calculations possible; $-=$ not relevant. Number of individuals in square brackets.

\begin{tabular}{lllll}
\hline Sex & days after capture 1 & days after capture 2 & $\sim$ distance capture 1 and $2(\mathrm{~m})$ & $\sim$ distance capture2 and $3(\mathrm{~m})$ \\
\hline $\mathrm{J} \mathrm{[2]}$ & $66(27-105)[2]$ & $108[1]$ & $0[1] /$ na $[2]$ & na [1] \\
F [13] & $84(9-203)[13]$ & $70(44-108)[3]$ & $59(5-180)[10] /$ na [3] & $20(10-30)[2]$ \\
M [6] & $107(15-191)[6]$ & - & $71(10-170)[4] /$ na $[2]$ & - \\
\hline
\end{tabular}



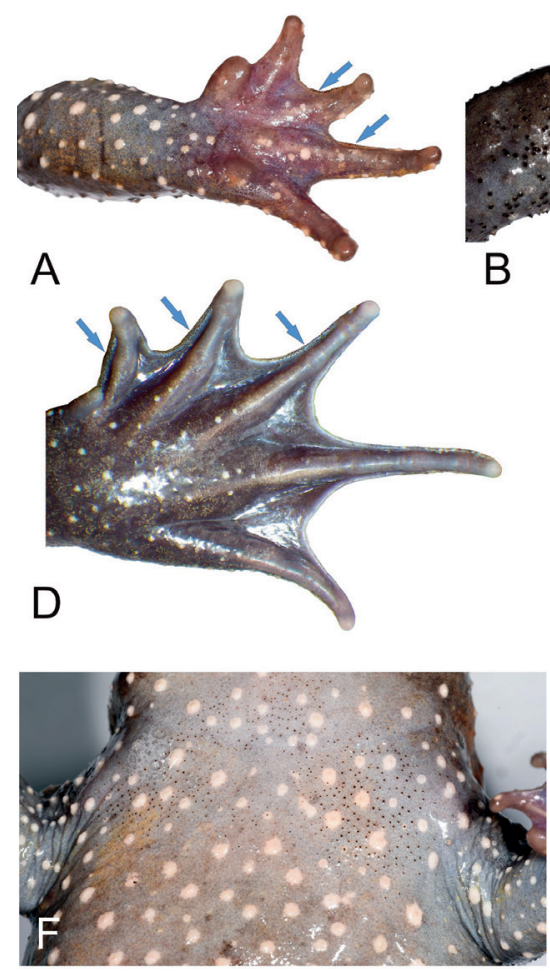

B
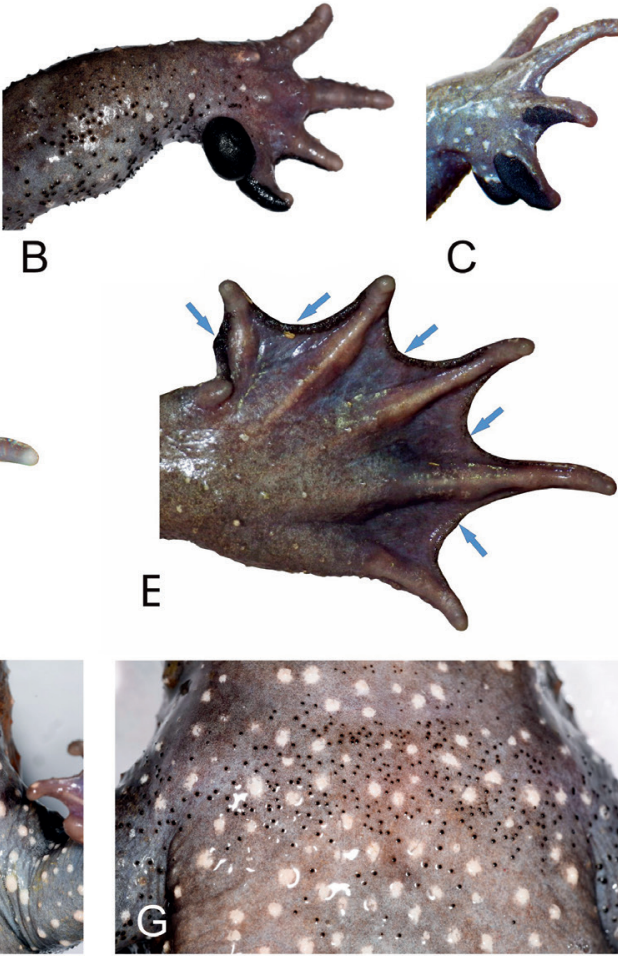

Fig. 5. Nuptial pads and keratinised excrescenses displayed by Latonia nigriventer individuals during breeding season. A) Hand of female individual with keratinised excrescences between fingers 1-2 and 2-3 (May); B) hand of male individual with distinct nuptial pads and keratinised excrescences on arm in ventral view (May); C) nuptial pads of male individual in dorsolateral view (May); D) webbing of female individual with a narrow rim of keratinised excrescences present on outer webbing edge (midFebruary); E) webbing of male individual with distinct rim of keratinised excrescences on outer webbing edge (midFebruary); keratinised excrescences on thorax as displayed by some female (F) and male $(\mathrm{G})$ individuals in May. Blue arrows indicate the webbing parts on which excrescences have been observed by us. Images were cut out of photos of live individuals with Photoshop CS2 software ( $v$ 9.0, Adobe Systems, San Jose, CA) and are not to scale. we therefore used this value as cut-off to distinguish adults from juveniles. Based on specimens $>66 \mathrm{~mm}$, we found no significant difference in the size-weight distribution of males and females (body condition calculated with the relative mass $\left(W_{\mathrm{r}}\right)$ condition index; Sztatecsny and Schabetsberger, 2005) using a MannWhitney-U test $(\mathrm{p}=0.615 ; \mathrm{N}$ (female $/ \mathrm{male})=64 / 44$; Fig. 6), nor did we detect distinct sexual dimorphism in morphometric measurements (Table 2). Slight differences were however seen in foot webbing (see S3 in the Supplement): females had slightly weaker webbing, with a distinct broadening of the toe III webbing usually at the $3^{\text {rd }}$ phalanx, and on toe IV at the $3^{\text {rd }}-4^{\text {th }}$ phalanx; whereas in males it usually was seen at the $2^{\text {nd }}$ phalanx at toe III and the $3^{\text {rd }}$ phalanx at toe IV. Forearms were strong in both sexes and could not be reliably used to differentiate females from males (for raw measurements see S4 in the Supplement).

\section{Tadpole morphology}

Tadpoles collected at two distinct sites in the ditch near Yesod HaMa'ala on 15 May 2015 agree with the description of Mendelssohn and Steinitz (1943) in having double keratodont rows and a network of black epidermal lines. They were small (total length $14 \mathrm{~mm}$ at Gosner stage 25 and $24 \mathrm{~mm}$ at Gosner stage 34), uniformly brown, with an unpigmented ventral side and ventral spiracle. The LTRF was 2/3(1), not considering double rows (Fig. 7). For a detailed description of the tadpoles see Appendix 3, for raw measurements see S5 in the Supplement.

The tadpoles of L. nigriventer are distinguished from those of the three other anuran species in this area (Bufotes variabilis (Pallas, 1769), H. savignyi and P. bedriagae) as well as those of Pelobates syriacus Boettger, 1889, by their medial ventral spiracle, distinct epidermal reticulations and double keratodont rows. Such biserial rows of keratodonts are a unique state for the basal anuran genera Discoglossus and Ascaphus, and are, with exception of Hoplobatrachus, not found in more advanced frogs (Grosjean et al., 2004). Dorsally, L. nigriventer tadpoles mostly resemble the ones of Bufotes in the position of their eyes and general appearance, but they lack the distinctly golden speckled venter as observed in the latter. The unpigmented venter of $L$. nigriventer tadpoles likewise serves as an immediate distinguishing characteristic from both Hyla and Pelophylax tadpoles that display a silvery venter.

Of the 40 tadpoles (Gosner stages roughly between 25 and 35) found on 15 May, 9 were successfully raised 

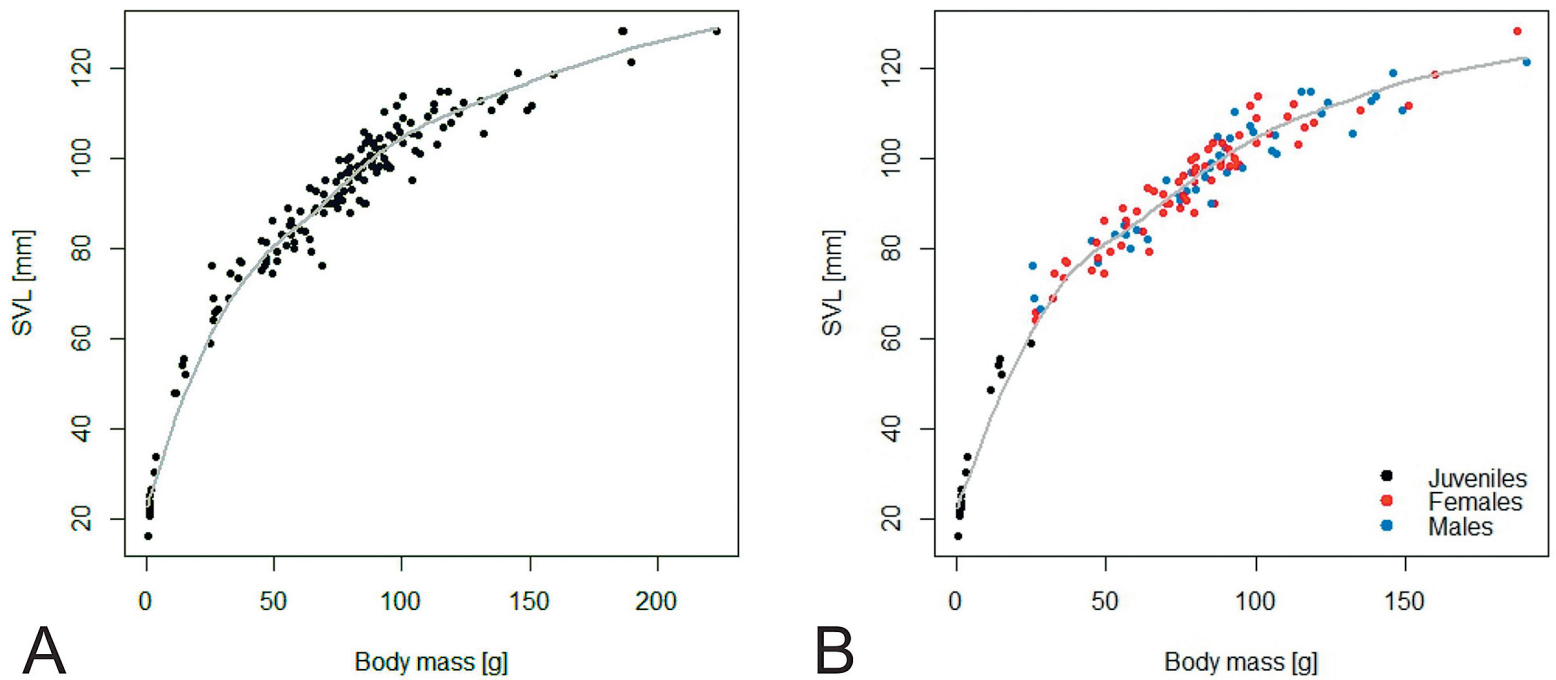

A

Body mass [g]
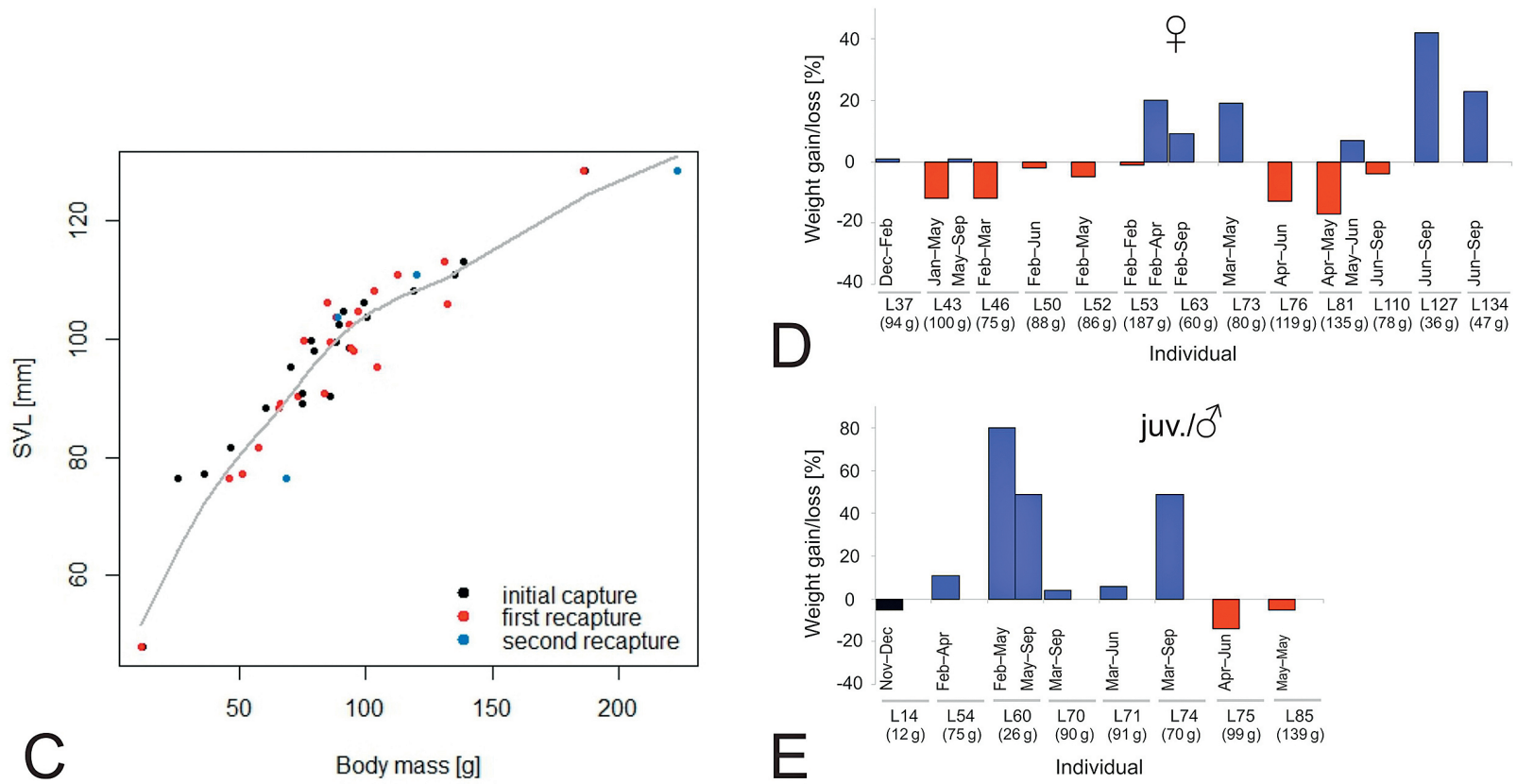

Fig. 6. Latonia nigriventer growth curves including data-driven LOESS (locally weighted scatterplot smoothing; Cleveland and Devlin, 1988) lines and weight gain/loss of recaptured individuals. A) Total captures including recaptures, B) captured individuals excluding recaptures, C) recaptured individuals, D) weight gain (blue) and loss (red) of recaptured females, E) weight gain (blue) and loss (red) of recaptured males as well as weight loss of the single recaptured juvenile (black). Initial capture weight of respective individual given in parentheses.

to post-metamorphs at the School of Marine Sciences (Ruppin Academic Center), Michmoret, where metamorphosis took place between 3-15 June 2015. Recently metamorphosed frogs had a SVL of 6-9 $\mathrm{mm}$. At the end of June, all post-metamorphs were transferred to the Garden of Zoological Research at Tel Aviv University for further rearing.

\section{Reproduction}

Besides the observation of tadpoles in mid-May, no direct observation of breeding has been made. The dissection of a dead L. nigriventer female that had been overrun by a tractor in mid-January revealed several hundred greyish-black oocytes with a diameter be- 


\begin{tabular}{|c|c|c|c|c|c|}
\hline & 우 & & ôे & & \\
\hline SVL & $97.2(74.6-128.4)$ & $\mathrm{N}=24$ & 98.9 & $(68.9-121.4)$ & $\mathrm{N}=19$ \\
\hline HW & $23.9(19.1-32.3)$ & $\mathrm{N}=24$ & 24.6 & $(11.8-33.1)$ & $\mathrm{N}=19$ \\
\hline BW & $54.7(36.2-75.0)$ & $\mathrm{N}=24$ & 53.0 & $(35.4-66.5)$ & $\mathrm{N}=19$ \\
\hline ED & $6.4 \quad(5.1-8.2)$ & $\mathrm{N}=24$ & 7.0 & $(4.8-9.3)$ & $\mathrm{N}=18$ \\
\hline $\mathrm{IO}$ & $13.2 \quad(7.8-18.7)$ & $\mathrm{N}=23$ & 13.1 & $(8.5-18.9)$ & $\mathrm{N}=19$ \\
\hline FS & $26.1(19.6-34.5)$ & $\mathrm{N}=23$ & 27.0 & $(13.1-35.3)$ & $\mathrm{N}=19$ \\
\hline CS & $16.7(12.2-29.9)$ & $\mathrm{N}=24$ & 16.1 & $(11.8-22.0)$ & $\mathrm{N}=19$ \\
\hline HL & $21.9(14.4-48.0)$ & $\mathrm{N}=24$ & 27.9 & $(12.4-48.3)$ & $\mathrm{N}=19$ \\
\hline $\mathrm{EF}$ & $23.9(19.1-32.3)$ & $\mathrm{N}=24$ & 35.6 & $(21.3-46.4)$ & $\mathrm{N}=19$ \\
\hline TL & $38.1(29.0-46.7)$ & $\mathrm{N}=20$ & 39.2 & $(28.1-48.6)$ & $\mathrm{N}=12$ \\
\hline
\end{tabular}

Table 2. Morphometric data for live adults of Latonia nigriventer. Measurements (in $\mathrm{mm}$ ) include mean (minimum-maximum) of following morphometric traits: body width (BW); tip of characteristic colour patch on forehead to snout (CS); eye diameter (ED); length of elbow to finger tip (EF); neck fold to snout (FS); hand length (HAL); head width at eyes (HW); minimal interorbital distance (IO); snoutvent length (SVL); tarsal length (TL). Number of measured individuals is indicated for each measurement.

tween 1.5-2 mm. From the available data and phylogenetic relatedness it can be hypothesised that at least some aspects of the reproduction are similar to Discoglossus, which are opportunistic breeders with a short and intense inguinal amplexus during which several batches of eggs are deposited and adhere to stones, aquatic plants or the bottom of the water body. According to the observations of (i) males with distinct nuptial pads and other keratinised excrescences from February to September, (ii) tadpoles in midMay (our observation) and August (Mendelssohn and
Steinitz, 1943), and (iii) the observed weight losses in recaptured females of L. nigriventer, we hypothesise a relatively prolonged reproductive period with egg depositions potentially taking place at least from March to June, and possible from February to September. This extended reproductive season, if confirmed, would be longer than in the three sympatric amphibian species, i.e., February/March-May in $B$. variabilis, March/April-June in H. savignyi, and May-August/September in P. bedriagae (Degani and Mendelssohn, 1984).
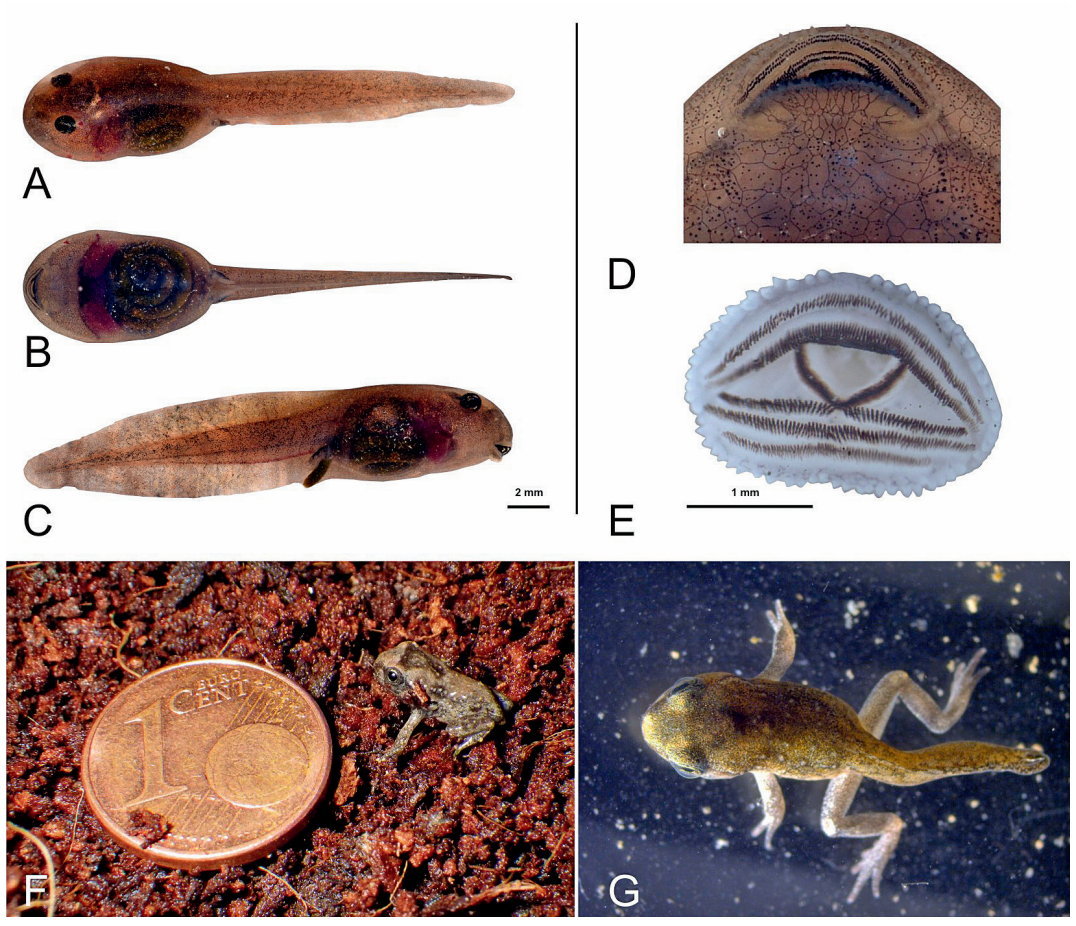

Fig. 7. Latonia nigriventer tadpole and (post-) metamorphic juveniles. A) Live L. nigriventer tadpole at Gosner stage 34 in dorsal view, B) ventral view and C) lateral view; D) oral disk of live tadpole displaying characteristic biserial keratodont rows and dense epidermal network of black lines E) oral disk of preserved tadpole (Gosner stage 34); F) individual shortly after metamorphosis. The tiny post-metamorph (SVL $\sim 6-9 \mathrm{~mm}$ ) already displays the typical colour patch on its forehead; G) metamorphosing individual. 

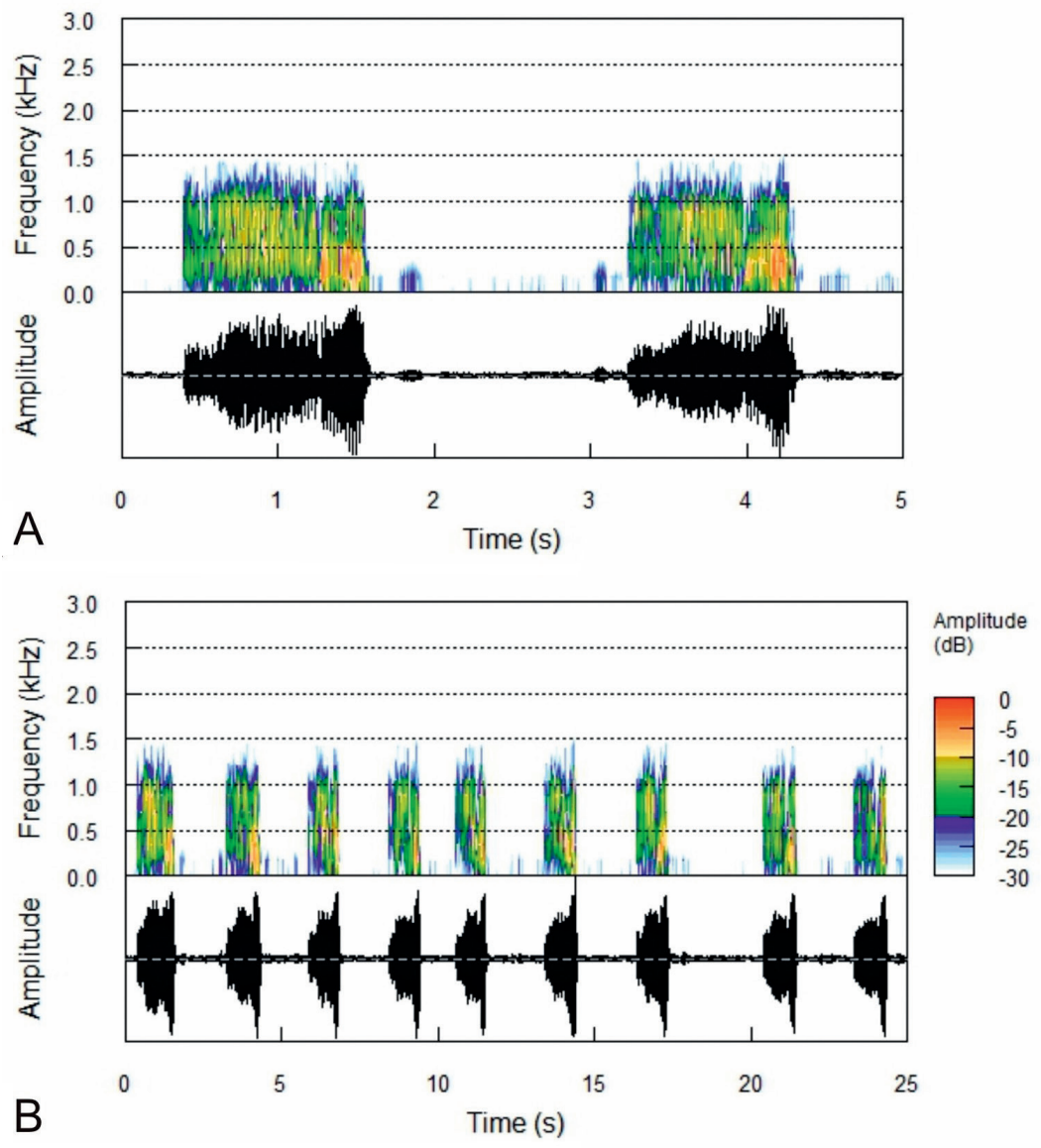

Fig. 8. Spectrogram and oscillogram of series of A) two and B) nine presumed advertisement calls of Latonia nigriventer. Note the low frequency $(\leq 1.5 \mathrm{kHz})$. The two notes (presumed expiratory and inspiratory) within each call are distinguishable, yet not separated by a silent interval. Sampling rate $44.1 \mathrm{kHz}$.

\section{Vocalisations}

Similar to Discoglossus (Weber, 1974; Glaw and Vences, 1991; Vences and Glaw, 1996), the calls heard from L. nigriventer were of very low intensity, low spectral frequency, and consisting of a presumed expiratory and a presumed inspiratory note. As the release calls of handled $L$. nigriventer sound very similar to the recorded calls, we assume the calls to be uttered at the water surface like in Discoglossus species. While we cannot ex- clude that other, more intense call types can be emitted by this species, the absence of externally visible vocal sacs in males makes it likely that their vocalisations mainly serve short-distance communication. Although we could only achieve provisional recordings under suboptimal conditions in captivity, which might have distorted some of the call features, we were able to record the calls of several male L. nigriventer individuals. Air temperature during recordings varied between $13.5-18{ }^{\circ} \mathrm{C}$ and water temperature between $14-15^{\circ} \mathrm{C}$.

\begin{tabular}{|c|c|c|c|c|c|c|c|}
\hline & \multicolumn{3}{|c|}{$\begin{array}{l}\text { Call duration (ms) } \\
(\mathrm{N}=72)\end{array}$} & \multirow{2}{*}{$\begin{array}{l}\text { Interval } \\
\text { between } \\
\text { calls }(\mathrm{ms}) \\
(\mathrm{N}=65)\end{array}$} & \multicolumn{3}{|c|}{$\begin{array}{l}\text { Dominant frequency }(\mathrm{Hz}) \\
(\mathrm{N}=72)\end{array}$} \\
\hline & $\begin{array}{l}\text { expiratory } \\
\text { note }\end{array}$ & $\begin{array}{l}\text { inspiratory } \\
\text { note }\end{array}$ & $\begin{array}{l}\text { total } \\
\text { call }\end{array}$ & & $\begin{array}{l}\text { expiratory } \\
\text { note }\end{array}$ & $\begin{array}{l}\text { inspiratory } \\
\text { note }\end{array}$ & $\begin{array}{l}\text { total } \\
\text { call }\end{array}$ \\
\hline Total & 671 & 291 & 962 & 787 & 795.2 & 531.6 & 775.5 \\
\hline SD & 115 & 28 & 123 & 609 & 65.3 & 299.3 & 80 \\
\hline
\end{tabular}

Table 3. Call features of the presumed advertisement calls recorded from a group of several individuals of Latonia nigriventer. 
As several males were kept together in the same aquarium, the following descriptive statistics refer to calls of various males in unknown proportions.

Calls were mostly uttered in a series and were separated from each other by short intervals of silence varying from 246-1606 ms (mean \pm SD: $787 \pm 609$ $\mathrm{ms} ; \mathrm{N}=65$ ). Each call consisted of two notes which we assume represent sounds produced by expiration (first note) followed by inspiration of air into the lungs (second note). Both notes were spectrally structured and pulsatile, but a clear distinction and count of pulses was not possible. The two notes of one call were not separated by a silent interval or distinct decrease in amplitude. Therefore, in the spectrogram the two notes are mostly recognisable by the somewhat lower frequency and higher intensity of the second (inspiratory) note (Fig. 8). Dominant frequency peak averaged over the total call (mean $\pm \mathrm{SD}$ ) was $775.5 \pm 80 \mathrm{~Hz}(\mathrm{~N}=72)$; frequency range was roughly between $0-1500 \mathrm{~Hz}$. Call duration $(\mathrm{N}=72)$ ranged between $725-1212 \mathrm{~ms}$, with the expiratory note being longer $(671 \pm 115 \mathrm{~ms})$ than the inspiratory note $(291 \pm 28 \mathrm{~ms})$ (Table 3$)$.

\section{Bd/Bsal screening, skin bacterial community, and defensive skin peptides}

The pathogen $B d$ was detected in $32 \%$ of the tested amphibian individuals $(\mathrm{n}=87)$ from northern Israel, while none were positive for $B s a l$. We found $B d$ in two amphibian species (L. nigriventer and $P$. bedriagae) and in three of the seven examined locations within the Hula Valley (Hula Nature Reserve, Kiryat Shmona and Yesod HaMa'ala). Infection loads for $B d$-positive individuals ranged between 1-311 genomic equivalents of zoospores per swab (Table 4).
Bacterial communities of L. nigriventer were comprised of Proteobacteria (56.7\%) with a high representation of Gammaproteobacteria (33.4\% of the overall community), Bacteroidetes (25.3\%) and Firmicutes (6.7\%) (Fig. 9 A). The 20 most abundant OTUs found on the skin of L. nigriventer represented $42 \%$ of the total reads (Fig. 9 B; S6 in the Supplement). The most abundant OTU (7\% of the total sequences) was assigned to an unspecified Chryseobacterium and present in $100 \%$ of the samples, although in varying abundance $(<1-24 \%$ of the reads). Comparisons based on weighted UniFrac distances did not reveal significant differences between (i) microbial communities from the ventral versus dorsal skin of L. nigriventer (PERMANOVA: $\mathrm{N}=27 ; \mathrm{p}=0.117$; Fig. $10 \mathrm{~A}$ ), (ii) ventral surfaces of females versus males (PERMANOVA: $\mathrm{N}=$ $15 ; \mathrm{p}=0.646$; Fig. $10 \mathrm{~B}$ ) or (iii) ventral surfaces of $B d$ positive versus $B d$-negative individuals (PERMANOVA: $\mathrm{N}=22 ; \mathrm{p}=0.283$; Fig. $10 \mathrm{C}$ ). However, we observed a significant shift in the ventral skin microbial community over time.

While no significant changes were observed between the ventral skin samples taken in mid-February and mid-April $(\mathrm{N}=13 ; \mathrm{p}=0.799)$ or between those collected in mid-April and the end of June $(\mathrm{N}=15$; $\mathrm{p}$ $=0.0 .093$ ), significant differences were detected for all other time-associated comparisons: mid-February late June $(\mathrm{N}=15 ; \mathrm{p}=0.012)$; mid-February - midSeptember $(\mathrm{N}=15 ; \mathrm{p}=0.001)$; late June - mid-September $(\mathrm{N}=17 ; \mathrm{p}=0.001)$ (Fig. $10 \mathrm{D})$.

The results obtained for the skin-associated bacterial communities of syntopic $P$. bedriagae were similar to those of L. nigriventer: no significant differences between ventral versus dorsal surfaces of the same individuals $(\mathrm{N}=14 ; \mathrm{p}=0.898)$ nor between ventral surfaces

\begin{tabular}{lllc}
\hline Species & Location & $\begin{array}{l}\text { No. of genomic } \\
\text { equivalents of } \\
\text { zoospores } \\
\text { per swab }\end{array}$ & $\begin{array}{l}\text { Analysed/ } \\
\text { Positive } \\
\text { for Bd }\end{array}$ \\
\hline Hyla savignyi & Einan Reserve & 0 & \\
Latonia nigriventer & Yesod HaMa'ala & $76(2-311)$ & $22 / 6$ \\
Pelophylax bedriagae & Eastern part of valley & 0 & $6 / 0$ \\
& Handaj area & 0 & $5 / 0$ \\
& Kiryat Shmona & 3 & $8 / 1$ \\
& Hula Nature Reserve & $45(3-132)$ & $7 / 4$ \\
Yesod HaMa'ala & $9(1-45)$ & $22 / 15$ \\
& Tel Dan & 0 & $8 / 0$ \\
\hline & & Total & $86 / 26$ \\
\hline
\end{tabular}

Table 4. Number of individuals per species tested for Batrachochytrium dendrobatidis including mean (range) of genomic equivalents of zoospores per swab for positive tested specimen. 

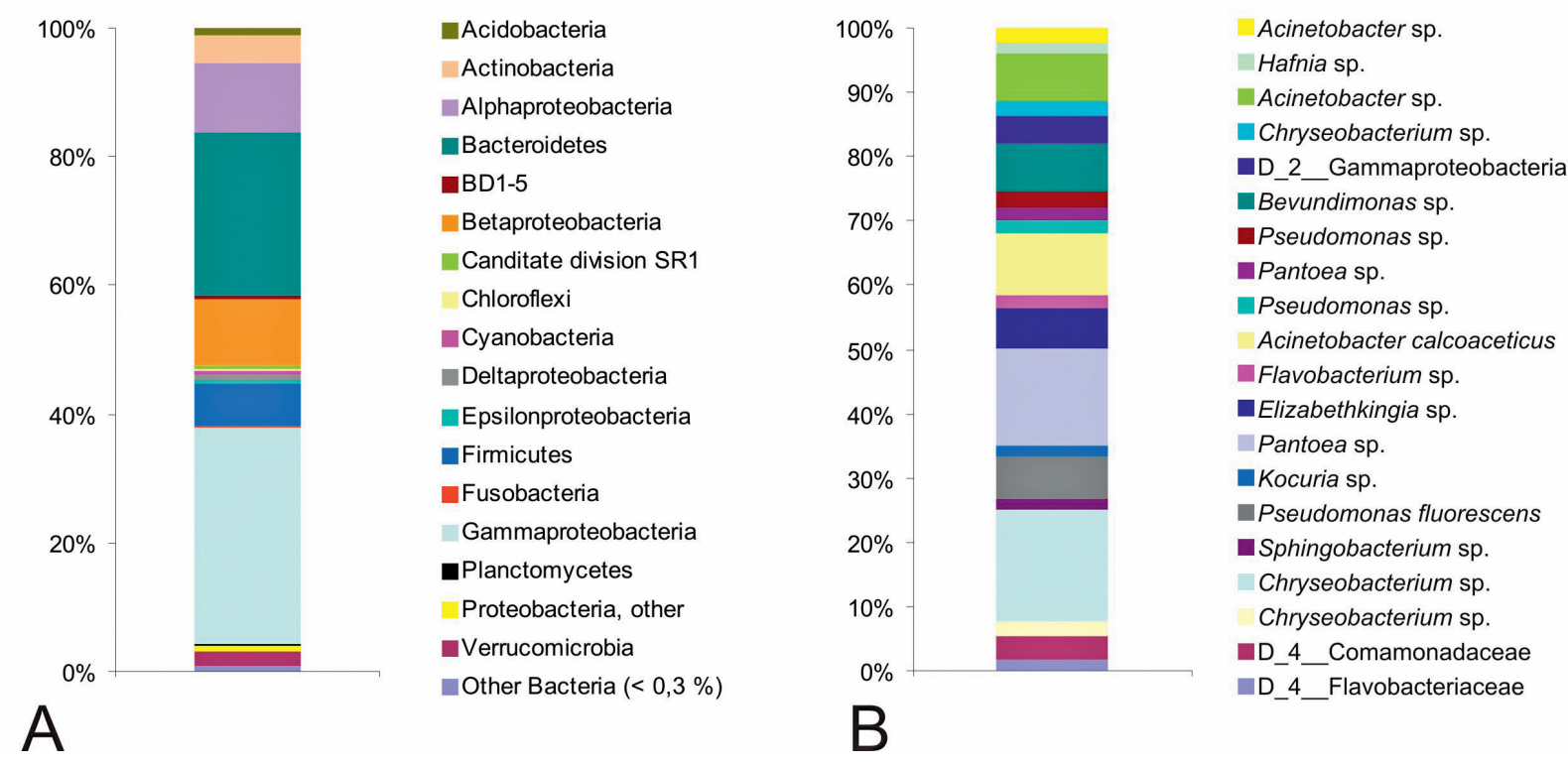

Fig. 9. Relative abundances of major bacterial taxa obtained from Latonia nigriventer skin samples in Yesod HaMa'ala as identified by the SILVA 119 database. The order of the taxa in columns corresponds to that in legends (ordered alphabetically). A) Abundances of dominant bacterial phylotypes; B) abundances of the 20 most frequent bacterial OTUs. (For detailed OTU IDs see S5 in the Supplement).

of $B d$-positive versus $B d$-negative individuals $(\mathrm{N}=22$; $\mathrm{p}=0.366$ ).

A comparison of the ventral skin-associated communities of L. nigriventer and P. bedriagae from the same location and same time-point revealed differences between the two species $(\mathrm{N}=17 ; \mathrm{p}=0.001$; Fig. $10 \mathrm{E})$. The core bacterial communities contained 30 OTUs (88\% of the core skin microbiota of L. nigriventer and $57 \%$ of that of P. bedriagae) that were present on the ventral skin of at least $75 \%$ of the individuals of both species (Fig. $10 \mathrm{~F}$ ).

The skin secretions collected from two different individuals and examined for peptide composition had significant amounts of hydrophobic peptides recovered after $\mathrm{C} 18$ enrichment. We detected a number of common peptide mass signals shared by both frog individuals. The mass ranges are suggestive of possible antimicrobial peptides (Table 5; S7 in the Supplement). In a growth inhibition assay, the mixture of peptides inhibited the growth of two different $B d$ isolates (JEL 197 and 'Section Line'; Fig. 11). At the highest concentration tested $(500 \mu \mathrm{g} / \mathrm{ml}), B d$ growth inhibition ranged from $51 \%$ to $91.5 \%$ against the Section Line isolate and $70-82 \%$ inhibition against the original type isolate JEL 197. Both isolates are among the global panzootic lineages (Schloegel et al., 2012; Piovia-Scott et al., 2015). Furthermore, the direct skin secretion solution was found to inhibit $B d$ by $35-36 \%$.

\section{Discussion}

Although amphibians as a group are relatively wellstudied, data deficiency still remains an issue that has to be overcome before conservation efforts can be effectively developed. Prior to its supposed extinction, the available information on the Hula painted frog was merely descriptive and only based on three adult specimens and two tadpoles. Without any details on its habitat requirements, activity patterns and reproductive biology, this secretive species went unnoticed for decades, despite numerous attempts to rediscover it in its former, but highly modified habitat. Even though habitat degradation remains a prime concern for most species, recently emerged pathogens have led to an increased awareness of disease-related threats. In this multifaceted threat scenario, basic biological information on the target species is still fundamental for developing risk assessments and conservation strategies, but is not sufficient in itself anymore.

In our study, we have provided detailed morphological descriptions of both adults and tadpoles and have compiled first findings on the behaviour, activity 

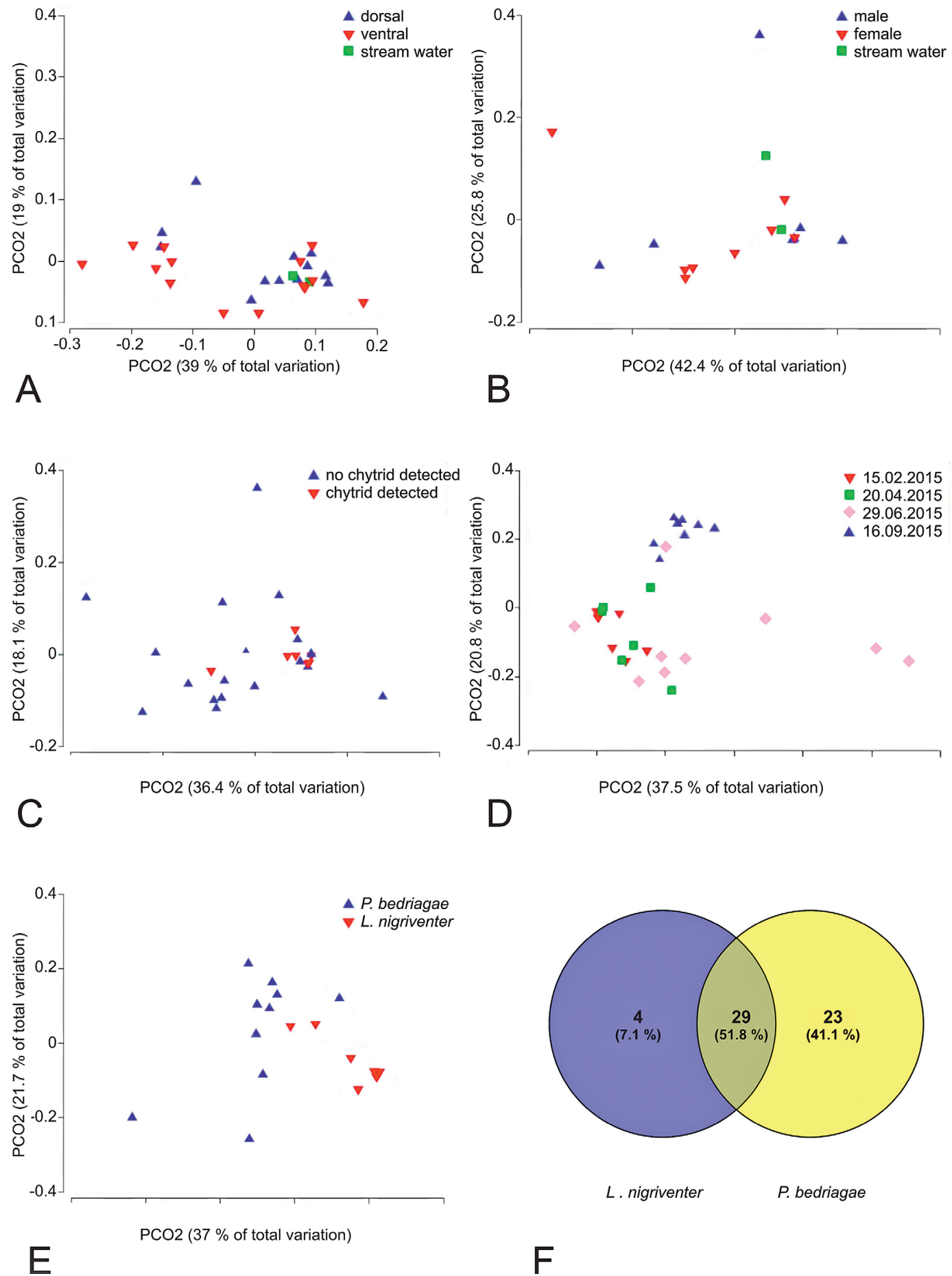

Fig. 10. Principal coordinates analysis plots of weighted UniFrac distances of the microbial communities associated with Latonia nigriventer and Pelophylax bedriagae. A) Comparison of dorsal and ventral surfaces in L. nigriventer; B) comparison of ventral skin microbial communities found in female and male L. nigriventer; C) comparison of L. nigriventer individuals tested positive and negative for chytrid (ventral surfaces only); D) seasonal changes in the ventral skin microbial community associated with L. nigriventer; E) comparison of the ventral skin microbial communities found in P. bedriagae and L. nigriventer; F) Venn diagram depicting the overlap of core microbial communities as obtained from ventral skin swabs of L. nigriventer and $P$. bedriagae captured at the same location and day. The minimum fraction of samples an OTU must be observed in was set to $75 \%$. 

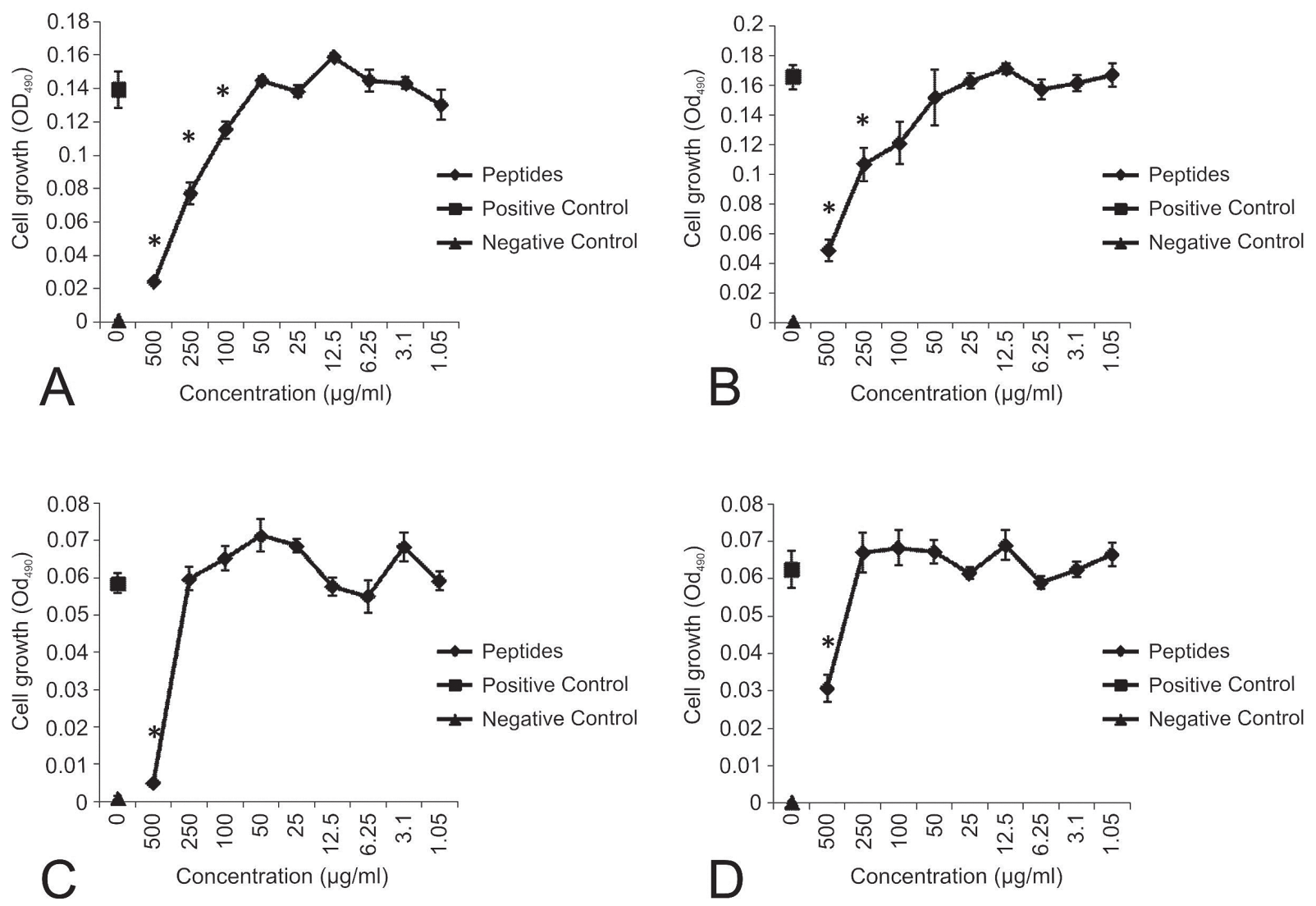

Fig. 11. Bd growth inhibition assays of two female Latonia nigriventer individuals against two $B d$ strains. A) Female 1 (SVL 90 mm; weight $86 \mathrm{~g}$ ) against $B d$ 197; B) female 2 (SVL $128 \mathrm{~mm}$; weight $187 \mathrm{~g}$ ) against $B d$ 197; C) female 1 against $B d$ Section Line strain; D) female 2 against $B d$ Section Line strain. Asterisks $\left(^{*}\right)$ indicate significantly less than positive control for growth by Student's $t$ test $(\mathrm{p} \leq 0.05)$.

\begin{tabular}{lcclll}
\hline Sample & SVL $(\mathrm{mm})$ & Mass $(\mathrm{g})$ & $\begin{array}{l}\text { Total } \\
\text { Peptides }(\mu \mathrm{g})\end{array}$ & $\begin{array}{l}\text { Peptides per } \\
\text { gram body } \\
\text { weight }(\mu \mathrm{g} / \mathrm{g})\end{array}$ & $\begin{array}{l}\text { Peptides/ml } \\
\text { of mucus }\end{array}$ \\
\hline L.nigriventer 1 & 90 & 86 & 6247.6 & 72.6 & 10418.1 \\
L.nigriventer 2 & 128 & 187 & 7824.6 & 41.8 & 8445.7 \\
\hline
\end{tabular}

Table 5. Quantity of peptides detected in the mucus of two Latonia nigriventer females. patterns and vocalisation of L. nigriventer as well as initial information on its habitat. Together with our preliminary results on the presence of $B d$ on the Hula painted frog, our findings are important means to direct future research and conservation management of this critically endangered amphibian.

Our surveys in the Hula Valley and adjacent regions of northern Israel confirmed that L. nigriventer is a localised species that occurs within and in close vicinity to the Hula Nature Reserve. This wetland site became Israel's first nature reserve in 1964 (Israel Nature and Parks Authority 2015) and is a closely monitored haven for a rich vertebrate fauna (Table S1) that - with exception of a fenced circular path - is not accessible to the public. By contrast, the site at Yesod HaMa'ala is subject to heavy anthropogenic influences, e.g. extensive rubbish dumping, petrol spills, near agricultural pesticide applications as well as occasionally freeroaming horses. The newly discovered large population at this heavily disturbed site not only demonstrates the adaptability of this rare frog to different environmental conditions, but is furthermore likely to be cru- 


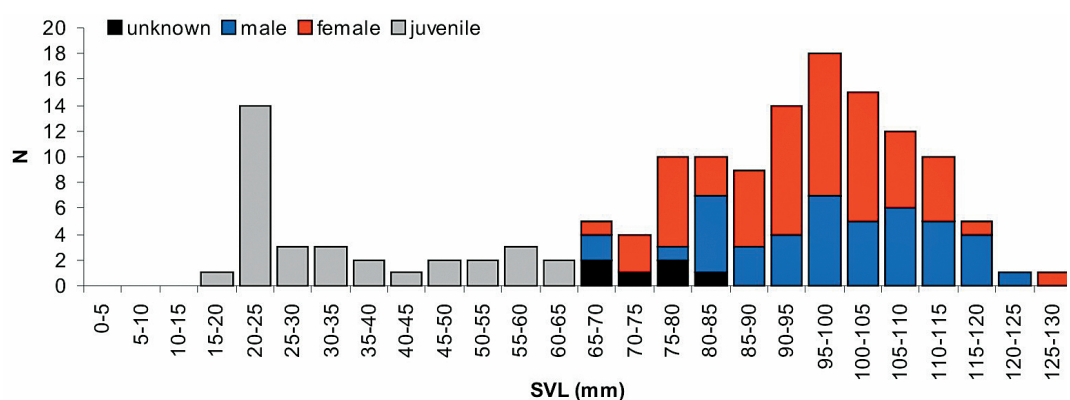

Fig. 12. Total numbers of detected Latonia nigriventer individuals per size cohort. cial for its overall survival. In addition, the confirmation of recent reproductive events at that site as well as the fact that adult individuals can reach snout-vent lengths of up to almost $130 \mathrm{~mm}$ while juveniles and tadpoles are comparatively tiny, illuminate aspects of the species' life history that will guide future conservation planning.

Latonia nigriventer is shy in its aquatic habitat, rarely seen active during the day, and apparently not emitting loud vocalisations. Given these elusive habits, additional undetected populations might exist in the Hula Valley. Nevertheless, it is most likely that L. nigriventer will be restricted to particular kinds of habitats that allow the large adults to hide in the aquatic habitat (e.g., in deep layers of aquatic vegetation and mud) as well as in the terrestrial environment. It is yet unclear whether our observation of less adult individuals staying in the water from September through January is associated with the rather sparse vegetation along and within the water during the colder months or simply a reflection of our sampling effort. Based on our knowledge on Discoglossus species we initially directed our sampling effort mainly on the terrestrial habitat. We therefore cannot rule out the possibility of L. nigriventer being present in its aquatic habitat year-round.

We acknowledge that our radio-tracking attempt only yielded preliminary insights and implanted or digested devices will be necessary to confirm the results. However, our capture-recapture data also reflect a reduced movement. This apparently low dispersal capability of the Hula painted frog and its extended presence in the breeding waters are a major difference in comparison to species of its sister genus Discoglossus. These smaller-sized frogs (SVL 36-80 mm) breed in a large variety of shallow and often ephemeral water bodies following episodes of rain and an increase of temperatures (Vences and Grossenbacher, 2012). While Discoglossus males might stay close to or in water bodies during some weeks for reproduction, females usually show aquatic habits only for reproduction. In contrast, the large-sized Hula painted frog was so far without exception found in the proximity of and mostly in permanent water bodies.

These seemingly more aquatic habits of $L$. nigriventer convey risks as well as opportunities for conservation. On one hand, the year-round dependence on specific aquatic habitats might leave the individuals particularly vulnerable to local environmental changes, especially during the hot and dry summer months. On the other hand, if indeed small, deep, densely vegetated, muddy and permanent ditches represent an optimal habitat for this species, it should be easy to engineer exactly this kind of habitat in different parts of the Hula Valley where drainages and canals are omnipresent.

Like the closely related Discoglossus species, we found L. nigriventer to apparently breed opportunistically whenever conditions are advantageous. However, the role of rainfall for triggering egg deposition in this rare frog that mostly dwells in permanent water bodies remains unclear. The comparatively few tadpoles and juveniles found (Fig. 12) suggest that reproduction and recruitment in Latonia is comparatively low, and populations might survive less favourable periods with low reproductive success due to the longevity of the adults. Although the large size of this frog suggests a rather long lifespan, this hypothesis requires further testing. In contrast, the rather aquatic habits and reproduction in permanent water bodies might reduce the dependence of Latonia on rainfall compared to species of its sister genus Discoglossus.

Even though a large number of Hula painted frogs were found in the newly discovered site near Yesod HaMa'ala (131 out of 137 individuals), the conditions at this site might not be optimal. We observed a variety of detrimental factors of anthropogenic origin that might affect larval stages and productivity of adults. One of those factors is the sheer quantity of plastic and metal waste in the ditch, the degradation by-products 
of which have already been found to affect larval development and reproduction in amphibians (Oehlmann et al., 2009; Severtsova and Gutierrez, 2013). Another potentially detrimental factor is the nearby pesticide application. Studies that addressed the effect of pesticides on amphibians have shown that exposures even to low concentrations of the most commonly applied pesticide atrazine result in the feminisation of male frogs and cause the retardation of larval development and growth (Hayes et al., 2002, 2006; Boone and James, 2003; Carr et al., 2003). So far, however, the impact of both rubbish deposition and pesticide application at that new site on the development and reproduction of Latonia remains purely speculative.

Apart from anthropogenic influences, the high percentage of injury found in adults and the overall low numbers of small individuals might indicate a high predatory pressure on the early life stages of $L$. nigriventer. Besides White-throated kingfishers (Halcyon smyrnensis (Linneaeus, 1758)) that are known to prey upon adult L. nigriventer (Biton et al., 2013), juveniles might fall prey to a plethora of widespread and abundant animals that are known or suspected to prey on amphibians and present at the locality, such as Western mosquitofish (Gambusia affinis (Baird \& Girard, 1853); Goodsell and Kats, 1999; Komak and Crossland, 2000; Segev et al., 2009), freshwater crustaceans (Gherardi and Micheli, 1989; Capolongo and Cilia, 1987), dragonfly nymphs (Stav et al., 2007), Caspian turtles (Mauremys caspica (Gmelin, 1774); Sidis and Gasith, 1985), lycosid spiders and carabid beetles (McCormick and Polis, 1982; Toledo, 2005), or larger frog individuals comprising conspecifics (Mendelssohn \& Steinitz, 1943) and P. bedriagae (own observations).

Our data show that the fungal pathogen, $B d$, is present on L. nigriventer (27\%) as well as on P. bedriagae in the Hula Valley. During our surveys in northern Israel, we did not observe mass mortality events in any amphibian species, nor did we notice skin lesions in any individual. This finding is not unexpected given $B d$ has not wreaked havoc in amphibian populations in much of the Old World, with the exception of Australia. Also for Europe only a limited number of incidences with $B d$-induced mortalities have been documented so far (Bosch et al., 2001; Bosch and Martínez-Solano, 2006; Bosch and Rincón, 2008). All in all, many species appear to coexist with $B d$ at low infection intensities (Spitzen-van der Sluijs et al., 2014). Albeit our study has relatively low sample size and we conducted $B d$ screening only during one season, we can hypoth- esise that the low infection levels observed in our study could be associated both with environment and hostassociated factors. In temperature experiments with $B d$ isolates, Piotrowski et al. (2004) showed that $B d$ optimally grows at temperatures between $10-25{ }^{\circ} \mathrm{C}$, and suggest that lower or higher temperatures may not induce epidemics. The high water temperatures $(>25$ ${ }^{\circ} \mathrm{C}$ ) prevailing in the investigated ditches during the summer months, could thus be one factor explaining the low prevalence and intensity of $B d$. Our observations that Latonia individuals do not seem to form dense aggregations, but keep some distance to each other might also have affected the ability of $B d$ to spread from individual to individual.

The presence of antimicrobial peptides in $L$. $n i$ griventer could also, in part, explain the observed low $B d$ prevalence and intensity, although we acknowledge that two screened individuals are not an adequate sample size for broad conclusions to be made. However, our results provide a baseline for all future studies that endeavour to analyse the innate immunity of $L$. $n i$ griventer. Furthermore, the cutaneous bacterial community could play a role in mitigating chytrid infection in these frogs; as a perspective for future studies it is worth mentioning that seven of the most abundant bacterial OTUs found on the skin of L. nigriventer belong to species or genera known to potentially exhibit antifungal activity (Harris et al., 2006; Woodhams et al., 2007; Lauer et al,. 2008; Becker et al., 2015). The infection dynamics of $B d$ are likely a complex interaction of external environmental parameters, host behaviour, and host immunity factors that may differ across life stages. However, continued monitoring of $B d$ infection rates as well as an identification of the $B d$ strain present in northern Israel remain important. Furthermore, minimising the anthropogenic impact at the localities and preventing the introduction of new amphibian pathogens by carefully disinfecting utilised equipment before and after usage at the respective sites are imperative.

Our findings have direct relevance for the ongoing restoration project in the Hula Valley which offers enormous opportunities for improving and extending this rare species' suitable habitat. In close collaboration with local stakeholders and the Israel Nature and Parks Authority we will design a prospective monitoring system for this species and continue to raise local awareness in order to improve conservation at known and potential other locations. Environmental DNA studies to detect further populations of L. nigriventer are currently underway. Even though none of the Lato- 
nia individuals discovered within the Hula Nature Reserve was found in an aquatic habitat, first eDNA results indicate that individuals are at least crossing one of the water bodies within the north-eastern part of the reserve (Renan et al., 2016).

As our first tadpole-rearing attempt proved fruitful, a further step will be to set up a captive breeding programme. Such a programme could tide this unique frog over the most critical early tadpole and juvenile stages enabling translocation of individuals to restored and newly created habitats within its presumed former range, which would help to increase the population size and promote the survival of the Hula painted frog.

\section{Acknowledgements}

This study was carried out with the help of funds granted by BIOPAT - Patenschaften für biologische Vielfalt e.V. and the Amphibian Conservation Fund by Stiftung Artenschutz and VDZ to MV, BP, SG and EG; by the Mohamed bin Zayed Species Conservation Fund (MBZ) to MV and BP; and by the U.S. Fish and Wildlife Services (USFWS) and the Israel Nature and Parks Authority (INPA) to SR, SG and EG. Skin peptide studies in the Rollins-Smith lab were supported by National Science Foundation (USA) grant IOS-1121758. We are grateful to Yael Ballon, Eliane Küpfer, Asaf Moran, Noa Truskanov (in alphabetic order), who have provided assistance during fieldwork, as well as Gilad Amir for reporting the first specimen found in Yesod HaMa'ala, and Shai, Muli and Yehuda Dabush for reporting the L. nigriventer roadkill. Furthermore, we thank the staff of the Hula Nature Reserve for providing access to areas not open to the public and patiently helping wherever help was needed; special thanks go to Yifat Artzi for logistic assistance and provision of office space. We also thank Giora Gigis, curator at the Beit Ussishkin Nature Museum located in Kibbutz Dan for assisting in night surveys and providing access to old documents on L. nigriventer. Above this, we are grateful to Meike Kondermann as well as Joana Sabino-Pinto for help with labwork and Boaz Shacham who allowed the examination of specimens in the HUJ collection under his care. Thanks are also due to Sabin Bhuju, Robert Geffers and Michael Jarek, who performed Illumina sequencing and sequence pre-processing. Last but not least, we thank the reviewers and editorial staff for their detailed comments and suggestions that improved our manuscript. Permits and authorisations were granted by the Israel Nature and Parks Authority. Tadpoles and metamorphs were reared under Permit number 2015/40926.

\section{References}

Altig R, McDiarmid RW. 1999. Body plan: development and morphology. Pp. 24-51 in: McDiarmid RW, Altig R, eds, Tadpoles: The Biology of Anuran Larvae. Chicago University Press, Chicago.
Aronesty E. 2011. ea-utils: command-line tools for processing biological sequencing data. Available at http://code.google. com/p/ea-utils (accessed 20 Nov 2015).

Aronesty E. 2013. Comparison of sequencing utility programs. The Open Bioinformatics Journal 7: 1-8.

Baillie JEM, Griffiths J, Turvey ST, Loh J, Collen B. 2010. Evolution Lost: Status and Trends of the World's Vertebrates. Zoological Society of London, London.

Becker MH, Walke JB, Murrill L, Woodhams DC, Reinert LK, Rollins-Smith LA, Burzynski EA, Umile TP, Minibole KPC, Belden LK. 2015. Phylogenetic distribution of symbiotic bacteria from Panamanian amphibians that inhibit growth of the lethal fungal pathogen Batrachochytrium dendrobatidis. Molecular Ecology 24: 1628-1641.

Biton R, Geffen E, Vences M, Cohen O, Bailon S, Rabinovich R, Malka Y, Oron T, Boistel R, Brumfeld V, Gafny S. 2013. The rediscovered Hula painted frog is a living fossil. Nature Communications 4: 1959.

Blommers-Schlösser RMA. 1979. Biosystematics of the Malagasy frogs. I. Mantellinae (Ranidae). Beaufortia 352: 1-77.

Blooi M, Pasmans F, Longcore JE, Spitzen-van der Sluijs A, Vercammen F, Martel A. 2013. Duplex Real-Time PCR for rapid simultaneous detection of Batrachochytrium dendrobatidis and Batrachochytrium salamandrivorans in amphibian samples. Journal of Clinical Microbiology 51: 41734177.

Bokulich NA, Subramanian S, Faith JJ, Gevers D, Gordon JI, Knight R, Mills DA, Caporaso JG. 2013. Quality-filtering vastly improves diversity estimates from Illumina amplicon sequencing. Nature Methods 10: 57-59.

Boone MD, James SM. 2003. Interactions of an insecticide, herbicide, and natural stressors in amphibian community mesocosms. Ecological Applications 13: 829-841.

Bosch J, Martinez-Solano I, Garcia-Paris M. 2001. Evidence of a chytrid fungus infection involved in the decline of the common midwife toad (Alytes obstetricans) in protected areas of central Spain. Biological Conservation 97: 331-337.

Bosch J, Martínez-Solano I. 2006. Chytrid fungus infection related to unusual mortalities of Salamandra salamandra and Bufo bufo in the Peñalara Natural Park, Spain. Oryx 40: 84-89.

Bosch J, Rincón PA. 2008. Chytridiomycosis-mediated expansion of Bufo bufo in a montane area of Central Spain: an indirect effect of the disease. Diversity and Distributions 14: 637-643.

Boulenger GA. 1891. A synopsis of the tadpoles of the European batrachians. Pp 593-678 in: Proceedings of the Zoological Society of London, Blackwell Publishing Ltd, London.

Capolongo D, Cilia JL. 1987. Potamon fluviatile lanfrancoi, a new subspecies of a Mediterranean freshwater crab from the Maltese Islands (Crustacea, Decapoda, Potamidae). Annalen des Naturhistorischen Museums in Wien. Serie B 91: $\mathrm{p}$ 215-224.

Caporaso JG, Kuczynski J, Stombaugh J, Bittinger K, Bushman FD, Costello EK, Fierer N, Gonzalez Peña A, Goodrich JK, Gordon JI, Huttley GA, Kelley ST, Knights D, Koenig JE, Ley RE, Lozupone CA, McDonald D, Muegge BD, Pirrung M, Reeder J, Sevinsky JR, Turnbaugh PJ, Walters WA, Widman J, Yatsunenko T, Zaneveld J, Knight R. 2010. Qiime allows analysis of high-throughput community sequencing data. Nature Methods 7: 335-336. 
Carr JA, Gentles A, Smith EE, Goleman WL, Urquidi LJ, Thuett K, Kendall, RJ, Giesy JP, Gross TS, Solomon KR, van der Kraak G. 2003. Response of larval Xenopus laevis to atrazine: Assessment of growth, metamorphosis, and gonadal and laryngeal morphology. Environmental Toxicology and Chemistry 22: 396-405.

Clarke KR, Gorley RN. 2015. PRIMER v7: User Manual/Tutorial. PRIMER-E Ltd., Plymouth.

Cleveland WS, Devlin SJ. 1988. Locally weighted regression: an approach to regression analysis by local fitting. Journal of the American Statistical Association 83: 596-610.

Cohen-Shacham E, Dayan T, Feitelson E, de Groot RS 2011. Ecosystem service trade-offs in wetland management: drainage and rehabilitation of the Hula, Israel. Hydrological Sciences Journal 56: 1582-1601.

Colombo BM, Scalvenzi T, Benlamara S, Pollet N. 2015. Microbiota and mucosal immunity in amphibians. Frontiers in Immunology 6: 111.

Culp CE, Falkinham III JO, Belden LK. 2007. Identification of the natural bacterial microflora on the skin of eastern newts, bullfrog tadpoles and redback salamanders. Herpetologica 63: 66-71.

Degani G, Mendelssohn H. 1984. Amphibia. Pp 190-221 in: Alon A, eds, Plants and animals of the land of Israel. Misrad Habitachon Pub, Tel-Aviv.

Dimentman CH, Bromley HJ, Por FD. 1992. Lake Hula: reconstruction of the fauna and hydrobiology of a lost lake. The Israel Academy of Sciences and Humanitites, Jerusalem.

Edgar RC. 2010. Search and clustering orders of magnitude faster than BLAST. Bioinformatics 26: 2460-2461.

Edgar, RC, Haas, BJ, Clemente JC, Quince C, Knight R. 2011. UCHIME improves sensitivity and speed of chimera detection. Bioinformatics 27: 2194-2200.

Gherardi F, Micheli F. 1989. Relative growth and population structure of the freshwater crab, Potamon potamios palestinensis, in the Dead Sea area (Israel). Israel Journal of Zoology 36: 133-145.

Glaw F, Vences M. 1991. Bioacoustic differentiation in Painted frogs (Discoglossus). Amphibia-Reptilia 12: 385-394.

Goodsell JA, Kats LB. 1999. Effect of introduced mosquitofish on Pacific treefrogs and the role of alternative prey. Conservation Biology 13: 921-924.

Goren M, Ortal R. 1999. Biogeography, diversity and conservation of the inland water fish communities in Israel. Biological Conservation 89: 1-9.

Gosner KL. 1960. A simplified table for staging anuran embryos and larvae with notes on identification. Herpetologica 16: $183-190$.

Grosjean S, Vences M, Dubois A. 2004. Evolutionary significance of oral morphology in the carnivorous tadpoles of tiger frogs, genus Hoplobatrachus (Ranidae). Biological Journal of the Linnean Society 81: 171-181.

Harris, RN, James TY, Lauer A, Simon MS, Patel A. 2006. Amphibian pathogen Batrachochytrium dendrobatidis is inhibited by the cutaneous bacteria of amphibian species. EcoHealth 3: 53-56.

Hayes T, Haston K, Tsui M, Hoang A, Haeffele C, Vonk A. 2002. Herbicides: Feminization of male frogs in the wild. Nature 419: 895-896.

Hayes TB, Case P, Chui S, Chung D, Haeffele C, Haston K, Lee M, Mai VP, Marjuoa Y, Parker J, Tsui M. 2006. Pesticide mixtures, endocrine disruption, and amphibian declines: Are we underestimating the impact? Environmental Health Perspectives 114: 40-50.

Holden WM, Hanlon SM, Woodhams DC, Chappell TM, Wells HL, Glisson SM, McKenzie VJ, Knight R, Parris MJ, RollinsSmith LA. 2015. Skin bacteria provide early protection for newly metamorphosed southern leopard frogs (Rana sphenocephala) against the frog-killing fungus, Batrachochytrium dendrobatidis. Biological Conservation 187: 91-102.

Hyatt AD, Boyle DG, Olsen V, Boyle DB, Berger L, Obendorf D, Dalton A, Kriger K, Hero M, Hines H, Phillott R, Cambell R, Marantelli G, Gleason F, Colling A. 2007. Diagnostic assays and sampling protocols for the detection of Batrachochytrium dendrobatidis. Diseases of Aquatic Organisms 73: 175-192.

Israel Nature and Parks Authority. 2009. Israel Nature and Parks Authority. Available at http://www.parks.org.il/parks/ ParksAndReserves/hula/Pages/default.aspx (accessed 25 Sep 2015).

Johnson ML, Berger L, Philips L, Speare R. 2003. Fungicidal effects of chemical disinfectants, UV light, desiccation and heat on the amphibian chytrid Batrachochytrium dendrobatidis. Diseases of Aquatic Organisms 57: 255-260.

Kaplan D. 2012. Instability in newly-established wetlands? Trajectories of floristic change in the re-flooded Hula peatland, northern Israel. Mires and Peat 9: 1-10.

Kaplan D, Oron T, Gutman M. 1998. Development of macrophytic vegetation in the Agmon wetland of Israel by spontaneous colonization and reintroduction. Wetlands Ecology and Management 6: 143-150.

Komak S, Crossland MR. 2000. An assessment of the introduced mosquitofish (Gambusia affinis holbrooki) as a predator of eggs, hatchlings and tadpoles of native and non-native anurans. Wildlife Research 27: 185-189.

Kozich JJ, Westcott SL, Baxter NT, Highlander SK, Schloss PD. 2013. Development of a dual-index sequencing strategy and curation pipeline for analyzing amplicon sequence data on the MiSeq Illumina sequencing platform. Applied and Environmental Microbiology 79: 5112-5120.

Lauer A, Simon MA, Banning JL, André EA, Duncan K, Harris RN. 2007. Common cuteaneous bacteria from the Eastern Red-backed salamander can inhibit pathogenic fungi. Copeia 3: 630-640.

Lauer A, Simon MA, Banning JL, Lam BA, Harris RN. 2008. Diversity of cutaneous bacteria with antifungal activity isolated from female four-toed salamanders. The ISME Journal 2: 145-157.

Longcore JE, Pessier AP, Nichols DK. 1999. Batrachochytrium dendrobatidis gen. et sp. nov., a chytrid pathogenic to amphibians. Mycologia 91: 219-227.

McCormick S, Polis GA. 1982. Arthropods that prey on vertebrates. Biological Reviews 57: 29-58.

Mendelssohn H, Steinitz H. 1943. A new frog from Palestine. Copeia 4: 231-233.

Oehlmann J, Schulte-Oehlmann U, Kloas W, Jagnytsch O, Lutz I, Kusk KO, Wollenberger L, Santos EM, Paull GC, Van Look KJW, Tyler CR. 2009. A critical analysis of the biological impacts of plasticizers on wildlife. Philosophical Transactions of the Royal Society B 364: 2047-2062.

Pask JD, Woodhams DC, Rollins-Smith LA. 2012. The ebb and flow of antimicrobial skin peptides defends northern leop- 
ard frogs (Rana pipiens) against chytridiomycosis. Global Change Biology 18: 1231-1238.

Payne RJ. 2012. A longer-term perspective on human exploitation and management of peat wetlands: the Hula Valley, Israel. Mires and Peat 9: 1-9.

Piotrowski JS, Annis SL, Longcore JE. 2004. Physiology of Batrachochytrium dendrobatidis, a chytrid pathogen of amphibians. Mycologia 96: 9-15.

Piovia-Scott J, Pope K, Worth SJ, Rosenblum EB, Poorten T, Refsnider J, Rollins-Smith LA, Reinert LK, Wells HL, Rejmanek D, Lawler S, Foley J. 2015. Correlates of virulence in the frog-killing fungal pathogen: evidence from a California amphibian decline. The ISME Journal 9: 15701578.

Price MN, Dehal PS, Arkin AP. 2010. FastTree 2 - Approximately maximum-likelihood trees for large alignments. PLOS ONE: e9490.

Ramsey JP, Reinert LK, Harper LK, Woodhams DC, RollinsSmith LA. 2010. Immune defenses against a fungus linked to global amphibian declines in the South African clawed frog, Xenopus laevis. Infection and Immunity 78: 39813992.

Rebollar EA, Hughey MC, Harris RN, Domangue RJ, Medina D, Ibáñez R, Belden LK. 2014. The lethal fungus Batrachochytrium dendrobatidis is present in lowland tropical forests of far eastern Panamá. PLoS ONE: e95484.

Renan S, Gafny S, Geffen E. 2016. Using genetic monitoring to detect the Hula painted frog populations in the Hula Valley and testing the method efficiency for the monitoring of amphibians in Israel. In press in: Proceedings of the 52th Meeting of the Zoological Society of Israel, Israel Journal of Ecology and Evolution 62, Taylor \& Francis Online.

Resnick NM, Maloy WL, Guy HR, Zasloff M. 1991. A novel endopeptidase from Xenopus that recognizes alpha-helical secondary structure. Cell 66: 541-554.

Rideout JR, He Y, Navas-Molina JA, Walters WA, Ursell LK, Gibbons SM, Chase J, McDonald D, Gonzalez A, RobbinsPianka A, Clemente JC, Gilbert JA, Huse SM, Zhou H-W, Knight R, Caporaso JG. 2014. Subsampled open-reference clustering creates consistent, comprehensive OTU definitions and scales to billions of sequences. PeerJ 2: e545.

Rollins-Smith LA, Reinert LK, Miera V, Conlon JM. 2002. Antimicrobial peptide defenses of the Tarahumara frog, Rana tarahumarae. Biochemical and Biophysical Research Communications 297: 361-367.

Rollins-Smith LA, Woodhams DC, Reinert LK, Vredenburg VT, Briggs CJ, Nielsen PF, Conlon JM. 2006. Antimicrobial peptide defenses of the mountain yellow-legged frog (Rana muscosa). Developmental and Comparative Immunology 30: 831-842.

Sabino-Pinto J, Bletz MC, Islam MM, Shimizu N, Bhuju S, Geffers R, Jarek M, Kuraabayashi A, Vences M. 2016. Composition of the cutaneous bacterial community in Japanese amphibians: effects of captivity, host species, and body region. Microbial Ecology 2016: 1-10.

Schloegel LM, Toledo LF, Longcore JE, Greenspan SE, Vieira CA, Lee M, Zhao SA, Angen CW, Ferreira CM, Hipolito M, Da Vies AJ, Cuomo CA, Daszak PD, James TY. 2012. Novel, panzootic and hybrid genotypes of amphibian chytridiomycosis associates with the bullfrog trade. Molecular Ecology 21: 5162-5177.
Segev O, Mangel M, Blaustein L. 2009. Deleterious effects by mosquitofish (Gambusia affinis) on the endangered fire salamander (Salamandra infraimmaculata). Animal Conservation 12(1): 29-37.

Severtsova EA, Aguillon Gutierrez DR. 2013. Postembryonic development of anurans in ponds littered with metal-containing refuse (simulation experiments). Biology Bulletin 40: 738-747.

Sidis I, Gasith A. 1985. Food habits of the Caspian terrapin (Mauremys caspica rivulata) in unpolluted and polluted habitats in Israel. Journal of Herpetology 19: 108-115.

Spitzen-van der Sluijs A, Martel A, Hallmann CA, Bosman W, Garner TWJ, van Rooij P, Jooris R, Haesebrouck F, Pasmans F. 2014. Environmental determinants of recent endemism of Batrachochytrium dendrobatidis infections in amphibian assemblages in the absence of disease outbreaks. Conservation Biology 28: 1302-1311.

Stav G, Kotler BP, Blaustein L. 2007. Direct and indirect effects of dragonfly (Anax imperator) nymphs on green toad (Bufo viridis) tadpoles. Hydrobiologia 579: 85-93.

Steinborner ST, Waugh RJ, Bowie JH, Wallace JC, Tyler MJ, Ramsay SL. 1997. New caerin antibacterial peptides from the skin glands of the Australian tree frog Litoria xanthomera. Journal of Peptide Science 3: 181-185.

Steinitz H. 1955. Occurrence of Discoglossus nigriventer in Israel. Bulletin of the Research Council of Israel B 5: 192-193.

Sueur J, Aubin T, Simonis C. 2008. Equipment Review: Seewave, a free modular tool for sound analysis and synthesis. Bioacoustics 18: 213-226.

Sztatecsny M, Schabetsberger R. 2005. Into thin air: vertical migration, body condition, and quality of terrestrial habitats of alpine common toads, Bufo bufo. Canadian Journal of Zoology 83: 788-796.

Toledo L F. 2005. Predation of juvenile and adult anurans by invertebrates: current knowledge and perspectives. Herpetological Review 36: 395-399.

Vences M. 2012a. Discoglossus galganoi Capula, Nascetti, Lanza, Bullini und Crespo, 1985 - Iberischer Scheibenzüngler. Pp. 187-211 in: Grossenbacher K, ed, Handbuch der Reptilien und Amphibien Europas. Vol. 5/1: Froschlurche (Anura) I - (Alytidae, Bombinatoridae, Pelodytidae, Pelobatidae). AULA-Verlag, Wiebelsheim.

Vences M. 2012b. Discoglossus pictus Otth, 1837 - Gemalter Scheibenzüngler. Pp. 225-248 in: Grossenbacher K, ed, Handbuch der Reptilien und Amphibien Europas. Vol. 5/1: Froschlurche (Anura) I - (Alytidae, Bombinatoridae, Pelodytidae, Pelobatidae). AULA-Verlag, Wiebelsheim.

Vences M, Glaw F. 1996. Further investigations on Discoglossus bioacoustics: Relationship between $D$. galganoi galganoi, D. G. jeanneae and D. pictus scovazzi. Amphibia-Reptilia 17: 333-340.

Vences M, Grossenbacher K. 2012. 2.2.1.2. Unterfamilie Discoglossinae Günther, 1858; Gattung Discoglossus Otth, 1837 - Scheibenzüngler. Pp. 177-185 in: Grossenbacher K, ed, Handbuch der Reptilien und Amphibien Europas. Vol. 5/1: Froschlurche (Anura) I- (Alytidae, Bombinatoridae, Pelodytidae, Pelobatidae). AULA-Verlag, Wiebelsheim.

Wang Q, Garrity GM, Tiedje JM, Cole JR. 2007. Naive Bayesian classifier for rapid assignment of rRNA sequences into new bacterial taxonomy. Applied and Environmental Microbiology 73: 5261-5267. 
Weber E. 1974. Vergleichende Untersuchungen zur Bioakustik von Discoglossus pictus Otth 1837 und D. sardus Tschudi 1837 (Discoglossidae, Anura). Zoologische Jahrbücher (Physiologie) 18: 40-84.

Woodhams DC, Vredenburg VT, Simon MA, Billheimer D, Shakhtour B, Shyr Y, Briggs CJ, Rollins-Smith LA, Harris RN. 2007. Symbiotic bacteria contribute to innate immune defenses of the threatened mountain yellow-legged frog, Rana muscosa. Biological Conservation 138: 390-398.

Received: 18 March 2016

Revised and accepted: 8 July 2016

Published online: 13 February 2017

Editor: J.W. Arntzen 


\section{Online supplementary material}

S1. Rarefaction curve of bacterial OTUs from cutaneous bacterial communities of Latonia nigriventer compiled using Chaol estimation. All quality sequence reads (250-253 bp) were clustered with UCLUST (97\% similarity cut-off) prior to calculation of alpha diversity.

S2. List of species (vertebrates and selected macroinvertebrates) observed at the two main study sites.

S3. Webbing differences between female (left) and male (right) individuals of L. nigriventer. SVL (female -male): A) 80-82 mm; B) 106-105 mm; C) 107-109 mm; D) 112-114 mm. Images were cut from original photos of living individuals using Photoshop CS2 software (v 9.0, Adobe Systems, San Jose, CA) and are not to scale.

S4. Raw measurements of captured individuals of Latonia nigriventer. AH =air humidity; aqu (e) = aquatic, partly exposed; aqu (s) = aquatic, fully submerged; AT = air temperature; BW = body width; $\mathrm{CA}=$ capture circumstances; $\mathrm{CL}=$ cloud coverage; $\mathrm{CS}=$ tip of characteristic colour patch on forehead to snout; $\mathrm{ED}=$ eye diameter; $\mathrm{EF}=$ length of elbow to finger tip; F = female; FS = neck fold to snout; HAL = hand length; HW = head width at eyes; IND = individual ID; $\mathrm{IO}=$ minimal interorbital distance; $\mathrm{J}=$ juvenile; $\mathrm{LT}=$ tarsal length; $\mathrm{M}=$ male; $\mathrm{RC}=$ recapture; Res $=$ Reserve; $\mathrm{SVL}=$ snout-vent length; terr $(\mathrm{e})=$ terrestrial, exposed; terr $(\mathrm{h})=$ terrestrial, in hide; WE = Weight; YHM $=$ Yesod HaMa'ala; $-=$ missing values $;{ }^{1}=$ hidden beneath leaf $/$ reed litter; ${ }^{2}=$ hidden in small burrow or cavity; ${ }^{3}=$ hidden beneath grass tufts; ${ }^{4}=$ hidden under wooden log.

S5. Measurements of three preserved Latonia nigriventer tadpoles. The term keratodont row always refers to a biserial row. $\mathrm{A}_{1}$ (first upper keratodont row), $\mathrm{A}_{2}$ (second upper keratodont row), $\mathrm{A}_{1-2 \text { den }}$ (density of the keratodonts in row $A_{1-2}$ ), $A_{1-2 \text { dist }}$ (distance between rows $A_{1-2}$, measured between outer biserial rows at centre of oral disk), $A_{1-2}$ num (number of keratodonts in $\mathrm{A}_{1-2}$ ), $\mathrm{BH}$ (maximal body height), BL (body length), BW (maximal body width), DF (dorsal fin height at mid-tail), DG (size of the dorsal gap of marginal papillae), DMTH (distance of maximal tail height from the tail-body junction), ED (eye diameter), EH (eyes height - measured from the lower curve of the belly to the centre of the eye), HAB (height of the point where the axis of the tail myotomes contacts the body - measured from the lower curve of the belly), IND (inter-narial distance - measured from the centre), IOD (inter-orbital distance measured from the centre), JL (maximal jaw sheath length), LR (number of the lower rows of keratodonts), LTRF (labial tooth row formula), MP (marginal papillae), MTH (maximal tail height), ND (naris diameter), NH (naris height - measured from the lower curve of the belly to the centre of the naris), NP (naris-pupil distance), ODW (maximum oral disk width), $\mathrm{P}_{1}$ (first lower keratodont row), $\mathrm{P}_{1 \text { gap }}$ (medial gap in $\mathrm{P}_{1}$ ), $\mathrm{P}_{2}$ (second lower keratodont row), $\mathrm{P}_{3}$ (third lower keratodont row), $\mathrm{P}_{1-3 \text { den }}$ (density of the keratodonts in row $\mathrm{P}_{1-3}$ ), $\mathrm{P}_{1-3}$ dist (distance between rows $\mathrm{P}_{1-3}$, measured between outer biserial rows at centre of oral disk), $\mathrm{P}_{1-3 \text { num }}$ (number of keratodonts in row $\mathrm{P}_{1-3}$ ), $\mathrm{RN}$ (rostronarial distance), SBH (distance between snout and the point of maximal body height), SBW (distance between snout and the point of maximal body width), SE (snout-eye distance), SL (spiracle length - measured from the visible edges), SS (snout-spiracle distance), TAL (tail length), TH (tail height at the beginning of the tail), THM (tail height at mid-tail), Thorn-pap (thorn-shaped papillae), TL (total length), TMH (tail muscle height at the beginning of the tail), TMHM (tail muscle height at mid-tail), TMW (tail muscle width at the beginning of the tail), UR (number of the upper rows of keratodonts), VF (ventral fin height at mid-tail) and VL (vent tube length).

S6. List of the 20 most frequent bacterial OTUs obtained from Latonia nigriventer skin samples in Yesod HaMa'ala. $\mathrm{Ac}=$ Actinobacteria $; \mathrm{Ae}=$ Aeromonadaceae $; \mathrm{Al}=$ Alphaproteobacteria $; \mathrm{Ba}=$ Bacteroidetes $; \mathrm{Be}=$ Betaproteobacteria; $\mathrm{C}=$ Caulobacteriaceae; $\mathrm{E}=$ Enterobacteriaceae; $\mathrm{F}=$ Flavobacteriaceae; $\mathrm{G}=$ Gammaproteobacteria; $\mathrm{Mi}=\mathrm{Mic}-$ rococcaceae; $\mathrm{Mo}=$ Moraxellaceae; $\mathrm{P}=$ Pseudomonadaceae; $\mathrm{S}=$ Sphingobacteriaceae.

S7. MALDI-TOF MS of skin peptides of two female Latonia nigriventer individuals. Common mass signals are indicated by arrows. 


\section{Appendices}

Appendix 1 - Morphological description of adult specimens of Latonia nigriventer

Body width about two times head width. Head flattened and about as long as wide with a projecting snout that appears rounded in dorsal as well as lateral view. Nostrils positioned dorsally and closer to the tip of the snout than to the eyes. Eyes protruding, with heartshaped pupil and golden iris. A distinct transversal fold present in the neck (absent from species of Discoglossus, the sister genus of Latonia), varying in depth depending on the posture. In a bent-forward posture with stretched dorsal skin the fold merely discernible as a slight groove. Tympanic membrane indistinct and comparatively small. Forearms robust and muscular with four fingers. Fingers free with rounded or pointed tips (order of length: $1<4<2<3$ ). Hind limbs muscular with five toes (order of length: $1<2<5<3<4$ ). Metatarsalia largely separated by webbing. Webbing formula difficult to assess as subarticular tubercles absent: 1(1), 2(1), 3(1), 4(1), 5(1), with webbing starting more or less inconspicuous as dermal ridges. Snoutvent length (SVL; mean value (range)): $\$ \uparrow 94.8 \mathrm{~mm}$ (69.0-128.4 mm; $\mathrm{N}=64)$, ô के $98.0 \mathrm{~mm}(66.6-121.4$ $\mathrm{mm} ; \mathrm{N}=44$ ). Skin smooth with numerous small round tubercles on dorsal and ventral surfaces as well as limbs, but no distinct rows of tubercles. Tubercles on limbs closer to each other and less rounded, resulting in a rougher surface.

Colouration in life: Dorsally with ochre, brownish or auburn background colour and dark brown or olivegrey colour patches on head and dorsum; rarely with

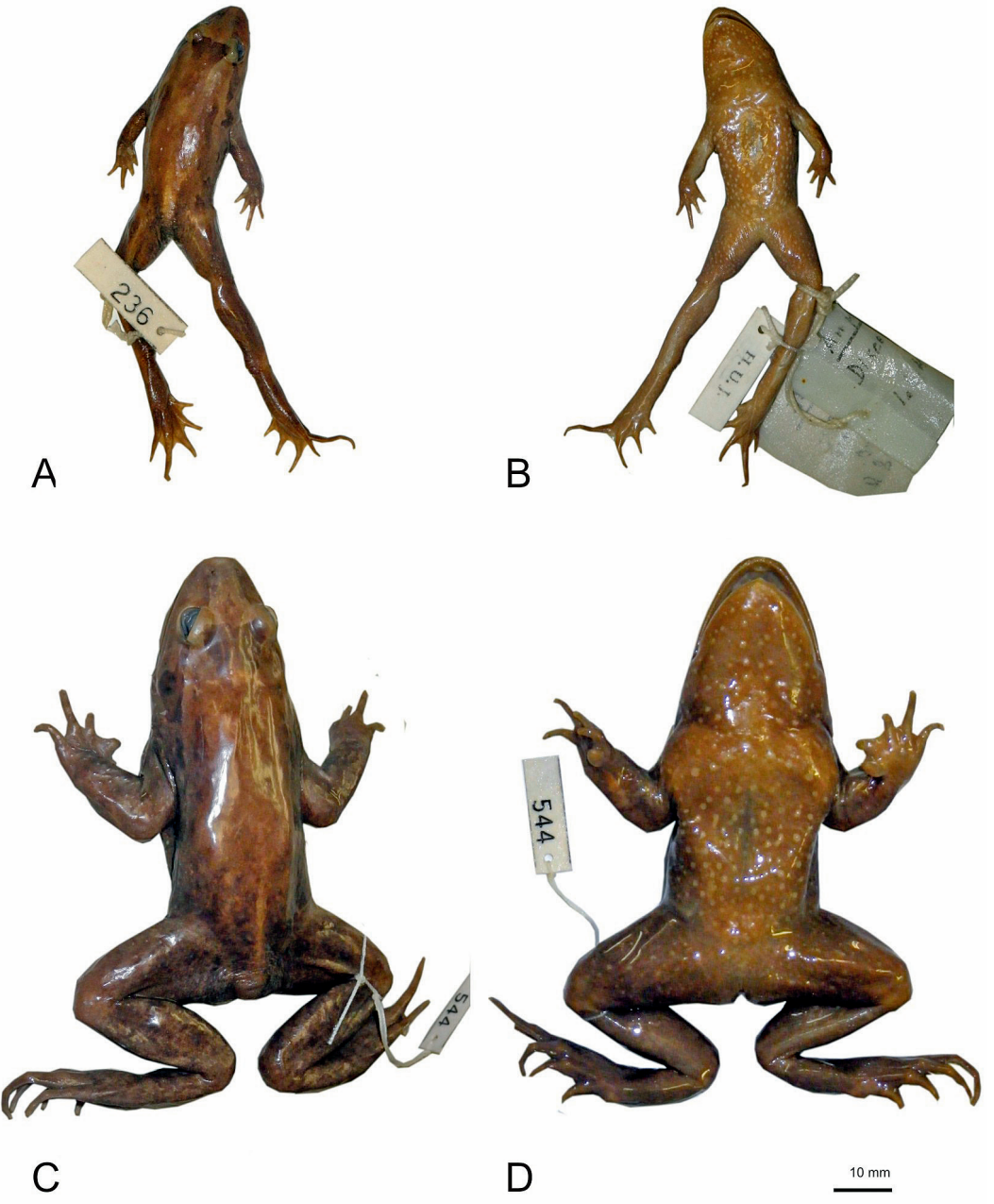

Fig. 13. Latonia nigriventer specimens preserved in the collection of the Hebrew University of Jerusalem. A) Subadult holotype (collection number HUJ 236) in dorsal view; B) HUJ 236 in ventral view; C) specimen collected in 1955 (collection number HUJ 544) in dorsal view; D) HUJ 544 in ventral view. Both individuals are assumed to be females. 
rusty coloured flecks. Characteristic dark V-shaped pattern on head with broad end positioned between eyes and posteriorly narrowing up to level of arms present in all L. nigriventer individuals. Likewise characteristic lateral stripes at head mostly starting posterior (sometimes anterior) of eyes and extending up to level of arms. Dark patterns often to some degree rimmed by a light beige line. Almost all individuals with an incomplete middorsal band of the background colour in the posterior part of the dorsum. No distinctly ocellated pattern, nor prominent middorsal band extending over the whole dorsum as present in the two colour morphs displayed by both, Discoglossus galganoi and D. pictus (Vences, 2012a, b), in any L. nigriventer individual examined. Ventrally, greyish-black with numerous characteristic white dots corresponding to raised tubercles and distributed more or less evenly across all ventral surfaces including arms, legs and plantar surfaces. In small juveniles (SVL 20-30 mm), white spots not raised as in adults. Border between ventral and dorsal pattern mostly gradually and rather inconspicuous; in some individuals colour transition associated with marbling in different hues of ochre, brown and grey that might include arms and legs. Femur and tibia often with more or less conspicuous dark crossbands. Single individuals almost without dorsal pattern and rather uniform. Ventral side sometimes rather light grey with inconspicuous white tubercles. Individuals found within deep leaf litter during winter months often displayed such a rather pale colouration.

\section{Appendix 2 - Morphological data on the holotype of Latonia nigriventer}

The holotype specimen of L. nigriventer (described as Discoglossus nigriventer Mendelssohn \& Steinitz, 1943) is preserved in the collection of the Hebrew University of Jerusalem under the collection number HUJ 236 (Fig. 13 A-B). It is a subadult specimen, possibly a female. We here provide some additional morphological data complementing those of Mendelssohn and Steinitz (1943). Upon examination in November 2011 (measurements by MV) it had a SVL of $39.9 \mathrm{~mm}$. Webbing formula was $1(2), 2 \mathrm{i}(2), 2 \mathrm{e}(2), 3 \mathrm{i}(2.5), 3 \mathrm{e}(2.5)$, $4 \mathrm{i}(2.5), 4 \mathrm{e}(2.75), 5(2.25)$. In addition, we also examined a second historical specimen collected in 1955 (no type status; Fig. $13 \mathrm{C}-\mathrm{D}$ ). This specimen, HUJ 544 , has faint remains of keratinised excrescences on some fingers but no clear nuptial pads. It therefore is likely a female. SVL is $76.6 \mathrm{~mm}$, webbing formula is
1(0.5), 2i(1.5), 2e(1.5), 3i(2), 3e(2), 4i(2.75), 4e(2.75), $5(2)$. Measurements of the two specimens (all in mm; type specimen measurements followed by those of the second specimen in parentheses) are as follows: head width 13.3 (24.4), head length 14.5 (ca. 26.5), tympanum diameter 2.3 (4.6), ED 4.0 (6.7), eye-nostril distance 3.7 (6.1), nostril-snout tip distance 3.0 (5.0), nostril-nostril distance 3.1 (4.7), HAL 9.4 (17.0), forelimb length 17.5 (not measured), hind limb length 52.5 (not measured), foot length including tarsus 25.5 (49.7), foot length 15.7 (not measured), tibia length 16.5 (34.5).

\section{Appendix 3 - Morphological description of tadpoles} of Latonia nigriventer

The following description refers to a single, preserved tadpole in developmental stage 34, fixed in $70 \%$ ethanol and preserved in 5\% formalin (field number ZCMV 12962, BL $8.9 \mathrm{~mm}$, TL $23.8 \mathrm{~mm}$ ). Abbreviations used: $\mathrm{A}_{1}$ (first upper biserial keratodont row), $\mathrm{A}_{2}$ (second upper biserial keratodont row), $A_{1-2}$ den (density of the keratodonts in biserial row $\mathrm{A}_{1-2}$ ), $\mathrm{A}_{1-2}$ dist (distance between biserial rows $A_{1-2}$, between outer biserial rows at centre of oral disk), $A_{1-2}$ num (number of keratodonts in $\mathrm{A}_{1-2}$ ), $\mathrm{BH}$ (maximum body height), BL (body length), BW (maximal body width), DF (dorsal fin height at mid-tail), DG (size of the dorsal gap of marginal papillae), DMTH (distance of maximal tail height from tailbody junction), ED (horizontal eye diameter), EH (eyes height - from the lower curve of the belly to the centre of the eye), HAB (body height where axis of tail myotomes contacts body - from the lower curve of belly), IND (inter-narial distance - from the centre), IOD (inter-orbital distance - from the centre), JL (maximum jaw sheath length), LR (number of lower rows of keratodonts), LTRF (labial tooth row formula), MP (marginal papillae), MTH (maximal tail height), ND (naris diameter), NH (naris height - from the lower curve of the belly to the centre of the naris), NP (narispupil distance), ODW (maximum oral disk width), $\mathrm{P}_{1}$ (first lower biserial keratodont row), $\mathrm{P}_{\text {gap }}$ (medial gap in $\mathrm{P}_{1}$ ), $\mathrm{P}_{2}$ (second lower biserial keratodont row), $\mathrm{P}_{3}$ (third lower biserial keratodont row), $\mathrm{P}_{1-3 \text { den }}$ (density of keratodonts in biserial row $\mathrm{P}_{1-3}$ ), $\mathrm{P}_{1-3}$ dist (distance between biserial rows $P_{1-3}$, between outer biserial rows at centre of oral disk), $\mathrm{P}_{1-3}$ num (number of biserial keratodonts in row $\mathrm{P}_{1-3}$ ), $\mathrm{RN}$ (rostro-narial distance), $\mathrm{SBH}$ (distance between snout and point of maximal body height), SBW (distance between snout and point of 
maximal body width), SE (snout-eye distance), SL (spiracle length - from the visible edges), SS (snoutspiracle distance), TAL (tail length), TH (tail height at beginning of tail), THM (tail height at mid-tail), Thorn-pap (thorn-shaped papillae), TL (total length), TMH (tail muscle height at beginning of tail), TMHM (tail muscle height at mid-tail), TMW (tail muscle width at beginning of tail), UR (number of upper rows of keratodonts), VF (ventral fin height at mid-tail) and VL (vent tube length).

In dorsal view, body elliptical with small constrictions of the body wall at the plane of the spiracle, maximal body width attained at anterior $1 / 3$ of midbody length (SBW $28.4 \%$ of BL), and snout rounded. In lateral view, body depressed (BW of 5.17 corresponds to $\mathrm{BH}$ ), maximal body height attained between 2/5 and 3/5 of body length (SBW $58 \%$ of BL), and snout sloping. Eyes medium-sized (ED $8 \%$ of BL), not visible from ventral view, positioned far dorsally (EH $64 \%$ of $\mathrm{BH}$ ) and directed laterally, situated between the 2/10 and 3/10 of the body length (SE 22\% of BL), medium distance between eyes (IOD $55 \%$ of BW). Small rounded nares (ND 3\% of BL), positioned at medium height ( $\mathrm{NH} 55 \%$ of $\mathrm{BH}$ ) and oriented anteriorly, situated distinctly closer to snout than to eye (RN 35\% of NP) and lower than eye (NH 85\% of EH), rather close distance between nares (IND $45 \%$ of IOD), dark spot posterior to nare present, other ornamentation absent. Spiracle crescentic, opening situated at centre of ventral side of the body (SL $4 \%$ of BL), directed posteriorly with inner wall present as a slight ridge, visible from ventral view, invisible from dorsal and lateral view; opening situated between the $2 / 5$ and $3 / 5$ of the body length (SS $56 \%$ of BL), Long medial vent tube (VL $19 \%$ of BL), attached directly to ventral fin. Tail moderately long (TAL $169 \%$ of BL), maximal tail height lower than body height (MTH $89 \%$ of BH), tail height at mid-tail lower than both body height and maximal tail height (THM 83\% of BH and THM 93\% of MTH), tail height at the beginning of tail slightly lower than body height (TH $92 \%$ of BH). Caudal musculature moderately developed (TMW $39 \%$ of BW, TMH $50 \%$ of BH and $57 \%$ of MTH, TMHM $32 \%$ of THM and $30 \%$ of MTH). Tail muscle does not reach tail tip (distance of tail muscle to tail tip 6\% of TAL). Moderately high fins (DF 105\% of TMHM, VF 110\% of TMHM), at mid tail ventral fin higher than dorsal fin (VF 104\% of DF). Dorsal fin inserts at the tail muscle posterior to the dorsal body-tail junction, first remains almost parallel to dorsal border of tail muscle, then rises gradually until the posterior $1 / 3$ of the tail where it increases to attain its maximal height, and then decreases gradually towards tail tip. Ventral fin originates at the ventral terminus of the body, rises minimally until middle of tail, and then remains almost parallel to the ventral border of the tail muscle until 1/3 of the tail where it likewise decreases gradually towards the tail tip. Maximal tail height located at anterior $1 / 3$ of tail (DMTH $35 \%$ of TAL), lateral line vein imperceptible, myosepta faintly discernible in lateral view in the proximal $2 / 5$ of the tail, point where the axis of the tail myotomes contacts the body located centred in body height (HAB $51 \%$ of BH). Tail tip rounded. Oral disk relatively large (ODW 29\% of $\mathrm{BL}$ and $49 \%$ of $\mathrm{BW}$ ), positioned and directed anteroventrally, not emarginated. Oral disk not visible from dorsal view, upper labium is a continuation of snout. Single row of marginal papillae interrupted by a narrow gap on the upper labium (DG $12 \%$ of ODW), gap on the lower labium absent. Total number of marginal papillae 64. Short and moderately sized conical papillae, longest marginal papillae measured $0.1 \mathrm{~mm}$. LTRF 2/3(1) after Altig and McDiarmid (1999), with two rows of keratondonts per ridge that are positioned at a distance of $0.5 \mathrm{~mm}$ from each other. $\mathrm{P}_{3}$ row generally biserial, but occasionally additional keratodons in between the two main rows. Very long $\mathrm{A}_{1}$ rows $(88 \%$ of ODW). Density of keratodonts varies from $64 / \mathrm{mm}$ to $76 / \mathrm{mm}, \mathrm{A}_{1} 73 / \mathrm{mm}$ (total 206). Narrow gap in the first posterior interrupted $\mathrm{P}_{1}$ rows $\left(\mathrm{P}_{\text {1gap }} 6 \%\right.$ of $\left.\mathrm{P}_{1}\right)$. Rows alignment regular. Short discernible keratodont $(0.08 \mathrm{~mm})$. Distal keratodont same length as those in the middle. Space between marginal papillae and keratodont rows only absent in $\mathrm{P}_{2}$. Partially keratinised jaw sheath, with the half part close to the edge being black and the remainder whitish coloured; finely pointed serrations; moderately wide jaw sheath (JW $51 \%$ of ODW) without medial concavity on the upper sheath. Lower jaw sheath V-shaped, partially keratinised and partially hidden by the upper jaw sheath (Table S3).

Colouration in life: Medium brown, translucent and with a uniformly distinct reticulation, inner anatomy well discernible. Dorsally, and with exception of the eye region, body covered by homogenous dark brown melanophoric pigments and golden speckles probably corresponding to guanophores. Tail of a slightly lighter hue than rest of body. Fins translucent, with dark brown spots of variable sizes and irregularly distribution, spot density higher in dorsal fin. Ventrally, oral disk and gular region reticulated, branchial regions reddish (Fig. 7). 
Colouration in preservative: Uniformly dark brown, body covered by homogenous dark melanophoric pigments giving it a granular appearance, colour slightly darker above brain and trunk region. Tail musculature overlaid by dark brown speckles. Fins translucent and, with exception of outer rim, covered with brown speckles. Venter including spiracle pale with irregularly distributed pale grey spots, spiracle hardly discernible, intestinal coils visible. Besides the regular pigmentation, whole body distinctly reticulated as was previously known to be characteristic for the tadpoles of only the genera Bombina, Discoglossus and Pelodytes (Boulenger, 1891). The fine pigmentary network is most apparent on fins and paler ground colour, e.g. venter.

Variation: in total, three tadpoles were investigated, two of which were in developmental stage 34 (ZCMV 12962 and ZCMV 12963) and one was at developmental stage 25 (ZCMV 12961). The observation of the other voucher specimens from the same locality shows the same general morphology and typical oral disk configuration of the described specimen, independent of their developmental stage. 